\title{
Parametric analysis of turning HSLA steel under minimum quantity lubrication (MQL) and nanofluids-based minimum quantity lubrication (NF-MQL): a concept of one-step sustainable machining
}

\author{
Hassan Javid ${ }^{1} \cdot$ Mirza Jahanzaib $^{1} \cdot$ Muhammad Jawad $^{1} \cdot$ Muhammad Asad Ali $^{1,2} \cdot$ Muhammad Umar Farooq $^{2}$. \\ Catalin I. Pruncu ${ }^{3,4}$ (D) Salman Hussain ${ }^{1}$
}

Received: 3 April 2021 / Accepted: 21 July 2021 / Published online: 13 August 2021

(C) The Author(s) 2021

\begin{abstract}
The requirement of cost-effective and ecological production systems is crucial in the competitive market. In this regard, the focus is shifted towards sustainable and cleaner machining processes. Besides the clean technologies, effective parametric control is required for machining materials (such as High Strength Low Alloy Steels) specifically designed for high strength applications having superior physio-chemical properties. Therefore, the machinability complexities require optimized solutions to reduce temperature elevation and tooling costs and improve machining of these materials. Complying to the market needs, this research examines the effectiveness of nanofluid on tool life, wear mechanisms, surface roughness (Ra), surface morphology, and material removal rate (MRR) in turning of $30 \mathrm{CrMnSiA}$ (HSLA) using minimum quantity lubrication (MQL) and $\mathrm{SiO}_{2}-\mathrm{H}_{2} \mathrm{O}$ nanofluids (NF-MQL). A systematic investigation based on physical phenomena involved is carried out considering four process parameters (cutting speed $\left(\mathrm{V}_{\mathrm{C}}\right)$, feed rate $\left(\mathrm{F}_{\mathrm{r}}\right)$, depth of cut $\left(\mathrm{D}_{\mathrm{OC}}\right)$, and mode of lubrication for machining. $\mathrm{F}_{\mathrm{r}}$ is found as the vital parameter for surface roughness while MRR is highly influenced by $\mathrm{D}_{\mathrm{OC}}$ regardless of lubrication approach. One-step sustainability technique is applied, in which process variables used for roughing conditions are analogous to attain surface comparable to finished machining without compromising process efficiency and demonstrate its feasibility through optimal settings under NFMQL. Multi-response optimization proved the NF-MQL machining condition as the best alternative which result in $28.34 \%$ and $5.09 \%$ improvements for surface roughness and MRR, respectively. Moreover, the use of $\mathrm{SiO}_{2}$ is recommended over MQL due to lower energy consumption, low tool wear, and better surface integrity, sustainable liquid, and related costs.
\end{abstract}

Keywords Minimum quantity lubrication $\cdot$ Nanofluids $\cdot$ HSLA steel $\cdot$ Surface roughness $\cdot$ Tool life $\cdot$ Sustainability

Muhammad Asad Ali

asad.ali@uet.edu.pk

Muhammad Umar Farooq

Umarmuf0@gmail.com

Catalin I. Pruncu

c.pruncu@imperial.ac.uk; Catalin.pruncu@strath.ac.uk

Hassan Javid

hasni515976@yahoo.com

Mirza Jahanzaib

jahan.zaib@uettaxila.edu.pk

Muhammad Jawad

engr.jawad@uettaxila.edu.pk
Salman Hussain

salman.hussain@uettaxila.edu.pk

1

Department of Industrial Engineering, University of Engineering and Technology, Taxila 47080, Pakistan

2 Department of Industrial and Manufacturing Engineering, University of Engineering and Technology, Lahore 54890, Pakistan

3 Department of Mechanical Engineering, Imperial College London, Exhibition Rd, London SW7 2AZ, UK

4 Design, Manufacturing and Engineering Management, University of Strathclyde, Glasgow, Scotland G1 1XJ, UK 


\section{Introduction}

In the modern industry, High Strength Low Alloy (HSLA) steel has gained attention due to high strength, toughness, and wear resistance. Because of these properties, these steels have numerous applications in high-speed turbines, aerospace engine parts, and submarine engine parts $[1,2]$. Quality and productivity are the essential requirements for these industrial products, are defined mainly by two attributes such as surface roughness (Ra) and material removal rate (MRR) [3]. These aspects highly depend on manufacturing methodology [4]. During conventional dry machining processes of these steels, machining attributes are not easily achieved due to aggressive cutting tool-material direct interaction. In dry machining, no cutting liquid is used which results in a rise in temperature that affects the thermal damage to the process surface which ultimately increases the work roughness [5]. To overcome these challenges, there should be lubrication between workpiece and tool. For this purpose, various coolants such as boron oil, water-oil emulsion, oil-based emulsion, and nanofluids were used during machining [6]. The summary of most used lubrication methods, especially based on nanofluids is provided in Table 1 .

However, the cost of lubricating oil is often much higher than the cost of the part and tool and they also are hazardous to the environment [1]. The cost of lubricant can be reduced by using minimum quantity lubrication (MQL) in which fluids is used in small quantities. MQL is much better technology than traditional flood cutting, with only 25 to $30 \%$ of liquids is required compared to traditional flood treatment $[15,16]$. Masoudi et al. [17] identified the MQL technique as one of the best practice during the turning of AISI 1045 when comparing dry, wet and MQL machining modes. However, some other studies showed that the MQL setup can be less effective in machining due to its low relative cooling efficiency [18]. Therefore, to efficiently obtain a good progress on MQL technology, nanofluids produced by the dispersion of nanoparticles in metalworking fluids are used. Commonly used nanoparticles are $\mathrm{Al}_{2} \mathrm{O}_{3}, \mathrm{SiO}_{2}, \mathrm{CuO}, \mathrm{SiC}$, graphene, and nanodiamonds etc. They helps in decreasing the temperature of the cutting zone and improves the thermal conductivity of liquids compared to the base cutting fluid which ultimately enhances the performance of cutting operation [7].

Quality cum productivity of turning parts greatly depend upon surface finish and material removal rate (MRR). It has been found that low value of surface roughness (Ra) enhances the fatigue life of machined parts [19]. To attain these requirements, suitable values of process parameters need to be selected [20]. There are many process parameters which affect the surface quality and MRR. These factors cover cutting fluids, machining parameters, and cutting tools. Das et al. [10] worked on different machining environments such as watersoluble oil, compressed air, and MQL applied $\mathrm{Al}_{2} \mathrm{O}_{3}$

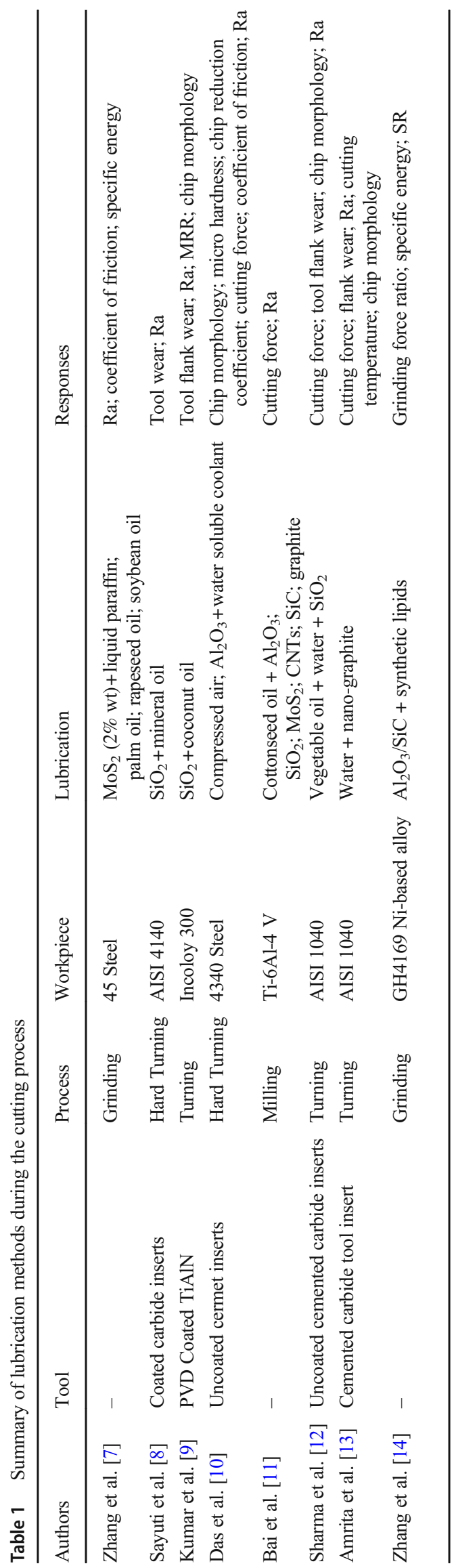


nanofluid. According to results, NF-MQL condition allows superior attributes in respect to other machining settings. Cong et al. [21] examined Ra of AISI 52100 and Q235B steel using $\mathrm{Al}_{2} \mathrm{O}_{3}$ nanoparticles with deionized water under MQL conditions. The results presented confirmed that better surface finish was achieved with nanoparticles concerning simple deionized water. Bai et al. [11] analyzed the performance of different nanofluids on cutting forces and surface finish. This research concluded that $\mathrm{Al}_{2} \mathrm{O}_{3}$ and $\mathrm{SiO}_{2}$ improved the output responses and these nanoparticles were environmentfriendly additives. Sharma et al. [12] worked on AISI 1040 steel during turning under various cutting conditions for instance: dry machining, MQL, and NF-MQL with $\mathrm{SiO}_{2}$ nanoparticles. It was cited that by adopting NF-MQL cutting system, surface roughness was reduced by $15 \%, 19.05 \%, 40.43 \%$ in comparison with flooded, MQL, and dry machining, respectively. Jeevan et al. [22] inspected surface roughness during the turning of AA6061 by using different environmentallyfriendly cutting fluids Jatropha and Pongamia oil, by using MQL method. According to their results, good quality surface was achieved at $F_{r}$ of $0.1 \mathrm{~mm} / \mathrm{rev}, D_{O C}$ of $0.5 \mathrm{~mm}$, and $V_{C}$ of $1600 \mathrm{rpm}$. Moreover, the better surface finish was achieved at low $V_{C}$ by using Jatropha oil in comparison with Pongamia oil. Amrita et al. [13] experimented on nanofluids in MQL for turning AISI 1040 steel. For MQL conditions, an air compressor with a nozzle was used to spray air at $10 \mathrm{ml} / \mathrm{min}$ flow rate. The results indicated that surface conditions improved by $28 \%$ compared to conventional cutting fluids. In another study, $\mathrm{SiO}_{2}$ nano lubrication was used during turning of steel AISI 4140 and results shown that surface finish increased by using $0.5 \%$ amount in mineral oil when the air pressure was low [8]. Khan et al. [23] worked on the comparative study of MQL and NFMQL by using $\mathrm{Al}_{2} \mathrm{O}_{3}$ as nanofluid during the machining of $\mathrm{D} 2$ steel. The surface roughness was reduced up to $12 \%$ in the case of NF-MQL. Zhang et al. [14] reported an work on NF-MQL machining using $\mathrm{Al}_{2} \mathrm{O}_{3} / \mathrm{SiC}$ hybrid nanoparticles. It has resulted that better surface finish was achieved by 2:1 mixing of nanoparticles. Gangil et al. [24] revealed that spindle speed and $D_{O C}$ are significant factors for MRR during the turning of Al-7075. Abbas et al. [25] concluded that for obtaining Ra of $0.8 \mu \mathrm{m}$, the maximum expected MRR was of $5668 \mathrm{~mm}^{3} /$ min obtained at $V_{C}$ of $175 \mathrm{~m} / \mathrm{min}, F_{r}$ of $0.043 \mathrm{~mm} / \mathrm{rev}$ and $D_{O C}$ of $0.75 \mathrm{~mm}$. Jha et al. [26] used Taguchi approach for finding the optimal process variables for maximizing the MRR. They concluded that $D_{O C}$ was the most significant factor followed by speed and $F_{r}$ during turning of aluminum alloy.

The literature reveals that the cooling conditions play a massive role in obtaining better product performance. Nanolubrication containing nano sized particles in the base fluid could be effective method to reduce the friction between tool-workpiece interface as it plays sliding and rolling role at the point of interaction of both surfaces which ultimately results in improving the machining performance [27]. It is also noticed that $\mathrm{SiO}_{2}$ nanoparticles are brittle, tough, inexpensive, having better mechanical attributes exclusively in terms of hardness ( $\mathrm{HV}=1000 \mathrm{~kg}-\mathrm{f} / \mathrm{mm} 2)$, and commercially accessible in precise small size ranges between $5 \mathrm{~nm}$ and $100 \mathrm{~nm}$ [8]. The literature also revealed that mineral oils have bad impact on soil and water reservoirs under the ground due to their poor degradability $[28,29]$. So, they are very harmful for environment and human health. Distilled water is selected as base fluid due to it is easily availability and no side effect properties on environment. Moreover, from literature, it is also revealed that $\mathrm{SiO}_{2}-\mathrm{H}_{2} \mathrm{O}$ nanofluid has better properties such as better thermal conductivity and has comprehensive suspension stability in comparison with other nanofluids [30,31].

Therefore, an appropriate selection of the machining atmosphere is particularly important during machining of HSLA Steel (30CrMnSiA). Till now, most work has been done in investigating the effects of three most influencing parameters: $V_{C}, F_{r}$, and $D_{O C}$ using conventional cooling techniques. However, there is no study focused on using $\mathrm{SiO}_{2}$ nanoparticles into the conventional fluid (water) and taking mode of lubrication as a qualitative factor during machining of HSLA Steel (30CrMnSiA). As, $\mathrm{SiO}_{2}-\mathrm{H}_{2} \mathrm{O}$ nanofluid has better thermal conductivity and has comprehensive suspension stability. Therefore, in this research, we have embedded a systematic evaluation to detect the workpiece surface effect and material removal rate when is applied $\mathrm{MQL}$ and $\mathrm{SiO}_{2}-\mathrm{H}_{2} \mathrm{O}$ nanofluids (NF-MQL). Predictive machining performance models have been developed by using ANOVA providing a mechanistic understanding from the theoretical point of view. Additionally, desirability technique is utilized to get the optimal set of variables for multi-objective optimization which leads to a sustainable process.

\section{Materials and methods}

In the current research, HSLA Steel (30CrMnSiA) has been selected due to its numerous applications in high-speed turbines, automotive industry aerospace engine parts, and submarine engine parts. The chemical composition and mechanical attributes of HSLA Steel are presented in Table 2. HSLA steel workpiece having $26 \mathrm{~mm}$ diameter and $60 \mathrm{~mm}$ length has been employed for experimentation. The turning process has been carried out by using coated carbide inserts (CNMG 1204 04 WF 5015) having cutting edge angle $95^{\circ}$. A total of $0.25 \%$ by weight solution of cutting fluid is prepared for the experimentation. For this purpose, $0.5 \%$ by weight of $\mathrm{SiO}_{2}$ nanoparticles is added in 2 litters of water with constant ratio of anticorrosive agent. A $200 \mathrm{~W}$ sonication chamber is used to disperse nanoparticles in distilled water which is followed by $1-\mathrm{h}$ stirring using a magnetic stirrer. Sonication process is carried out for two hours for complete dispersion of nanoparticles and to get a homogenous mixture [32] as shown in Fig. 1(a). 
Table 2 Chemical composition and mechanical properties of HSLA Steel

\begin{tabular}{lllllllll}
\hline $\mathrm{S} \%$ & $\mathrm{P} \%$ & $\mathrm{Ni} \%$ & $\mathrm{Cu} \%$ & $\mathrm{C} \%$ & $\mathrm{Cr} \%$ & $\mathrm{Mn} \%$ & $\mathrm{Si} \%$ & $\mathrm{Fe} \%$ \\
0.01 & 0.01 & 0.03 & 0.07 & 0.34 & 0.92 & 0.95 & 1.03 & Balance \\
\hline Density $\left(\mathrm{kg} / \mathrm{m}^{3}\right)$ & & & 7932.52 & & \\
Hardness $[\mathrm{HRC}]$ & & & 30 & & & \\
Ultimate tensile (MPa) & & 231 & & \\
Yield stress (MPa) & & 154 & & \\
\hline
\end{tabular}

Cutting speed $\left(V_{C}\right)$, feed rate $\left(F_{r}\right)$, and depth of cut $\left(D_{O C}\right)$ have been selected as process parameters whereas the mode of lubrication (MOL) as the categorical input parameter. The ranges of process variables have been finalized on the base of extensive literature [24] shown in Table 3, and thorough trial experiments. This has been also verified from the machining and Sandvik handbooks [33].

RSM has been employed for optimization of Ra and MRR. Various optimizations techniques such as Taguchi, Principal Component Analysis, Fuzzy Logic, Particle Swarm Analysis, RSM, and other statistical tools have been implemented by the researchers during turning of HSLA [30]. But RSM is considered as the one of the best modeling approaches in designing, developing, and improvement of a process, a product design [34]. RSM provides robust design of experiments and empirical modeling with superior confidence interval which not only saves time and cost of experimentation but also supports machinists achieving desired outcomes. With the help of RSM, the effect of single variables and their interactions can be judged on the responses one by one. It helps in developing the mathematical models which describe the input-output relationship. In RSM generally, results are lies in two types of models which are known as First and second-order models [2]. By using statistical software (Design Expert 12.0), 36 runs are designed based on RSM central composite design in current research. The number of experiments has been premeditated by using following Eq. (1) [20].

$\mathrm{n}=\mathrm{a}\left[2^{\mathrm{k}}+2 \mathrm{k}+\mathrm{m}\right]$

Table 3 Selected process parameters and its ranges

\begin{tabular}{lllllll}
\hline $\begin{array}{l}\text { Process } \\
\text { parameters }\end{array}$ & $\begin{array}{l}\text { Levels } \\
\text { Units }\end{array}$ & $\begin{array}{l}\text { Lowest } \\
-1.6818\end{array}$ & $\begin{array}{l}\text { Low } \\
-1\end{array}$ & $\begin{array}{l}\text { Medium } \\
0\end{array}$ & $\begin{array}{l}\text { High } \\
+1\end{array}$ & $\begin{array}{l}\text { Highest } \\
+1.6818\end{array}$ \\
\hline$V_{C}$ & $\mathrm{~m} / \mathrm{min}$ & 86.14 & 110 & 145 & 180 & 203.86 \\
$F_{r}$ & $\mathrm{~mm} / \mathrm{rev}$ & 0.07 & 0.10 & 0.15 & 0.20 & 0.23 \\
$D_{O C}$ & $\mathrm{Mm}$ & 0.10 & 0.3 & 0.6 & 0.9 & 1.10 \\
$M O L$ & & NF-MQL & & MQL \\
\hline
\end{tabular}

where "n" is the total number of conducted experiments, "a" represents to categorical factors, " $k$ " to the input parameters while " $\mathrm{m}$ " to the center points for CCD. The experimentation was performed on CNC Lathe machine (Model: PUMA 2300, manufactured by Daewoo Heavy Industries and Machinery Ltd. Korea). The MQL setup was attached with machine separately. The lubrication flow rate and air pressure were kept constant at $7.5 \mathrm{ml} / \mathrm{min}$ and $5 \mathrm{bar}$, respectively. The nanofluid spray system was kept perpendicularly at approximately $35 \mathrm{~mm}$ distance away from the tool-workpiece interaction point. The schematic diagram of the preparation of nanofluids, the experimental setup for MQL and NF-MQL turning of HSLA steel and performance measures is shown in Fig. 1(ac). The standards opted for preparation of nano-fluids are on the guidelines of $[35,36]$. Surface roughness was quantified after each experimental run through Surface Roughness Meter (Model: SJ-410). The surface roughness is measured as Ra because of its wide acceptability in industry. To reduce the measurement error, three readings have been taken for each finished surface and average of readings taken as final reading during the measurement of Ra. There are many techniques for measuring MRR. But in the current study, MRR was measured by using the following Eq. (2) [3].

$\operatorname{MRR}=\left[\frac{W i-W f}{\rho^{*} t}\right]$

where " $t$ " and are the machining time and density of specific material selected for experimentation, respectively. While " $W_{i}$ " and " $W_{f}$ " are the weights of the workpiece before and after machining.

\section{Machinability results and discussion}

\subsection{Tool wear/life analysis}

In the field of conventional machining, cutting tool wear is defined as unwantedly removed material which ensues in the area where the cutting tool-workpiece is betrothed for cutting purpose and representing as the tool lifespan. Generally, the escalation in the speed of cut-action impacts the wear along with augmented the tool life [37]. The tool wear influences the surface characteristics for instance workpiece service quality, cutting force, efficiency, the energy consumption of a cutting process. As per ISO 3685 standard, there are multiple criteria for wear level attainment such as crater depth or width at rake face, as the most used. Moreover, it includes flank wear and notch wear occurred at the flank face of the machining tool [38]. An indispensable portion of the current study serves to investigate average flank wear and tribological mechanisms to wear during the HSLA steel turning process. This material consists of tremendous attributes and is widely utilized in 
Fig. 1 a Preparation of nanofluid, b MQL and NF-MQL turning

experimental setup

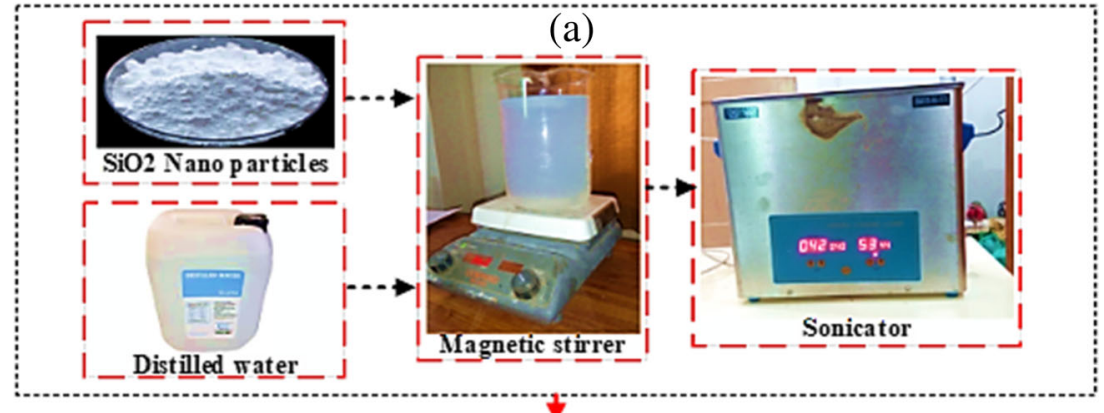

(b)

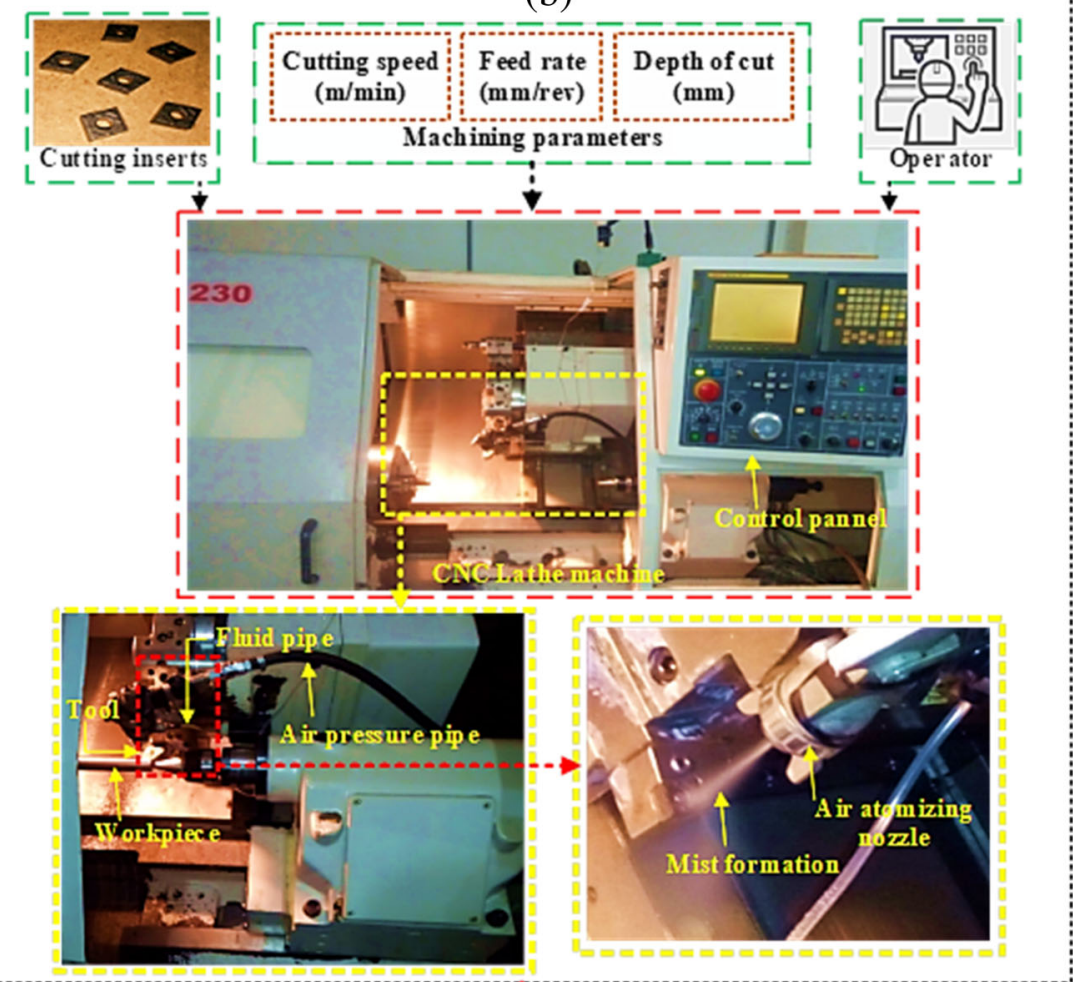

numerous applications of the manufacturing industry particularly machined under various sustainable cutting mediums. Tool life was used to measure by Taylor's tool life equation [39] as given in Eq. (3).

$\mathrm{VT}^{\mathrm{n}}=\mathrm{C}$

where "V" represents to the $V_{C}(\mathrm{~m} / \mathrm{min})$, "T" to the tool life (min), $n$ to the tool material based constant, and $\mathrm{C}$ to the toolworkpiece material based constantly. $\mathrm{C}$ is expressed as cutting speed for 1 min machining by the tool. The turning operation was carried out successfully on HSLA steel bar using CNC lathe machine to find out the value of " $\mathrm{C}$ ". In this experimentation, $D_{O C}$ and $F_{r}$ were kept at $0.6 \mathrm{~mm}$ and $0.15 \mathrm{~mm} / \mathrm{rev}$, respectively. Machining was started at cutting speed $220 \mathrm{~m} /$ min and using steps of $15 \mathrm{~m} / \mathrm{min}$ to determine the tool wear for MQL and NF-MQL methods of machining. It was found that flank wear was an important factor affecting the tool life which was measured and presented in Table 4.
For calculation of tool life, $0.3 \mathrm{~mm}$ flank wear criteria were used and that was observed at $V_{C} 261.66 \mathrm{~m} / \mathrm{min}$ and $292.85 \mathrm{~m} / \mathrm{min}$ for MQL and NF-MQL machining respectively. Tool wear observed after experimentation as given in Fig. 2. Flank wear was examined and recorded as given in

Table 4 Tool flank wear for MQL and NF-MQL machining

\begin{tabular}{llll}
\hline Run No. & $V_{C}$ & \multicolumn{2}{l}{ Tool flank wear $(\mathrm{mm})$} \\
\cline { 3 - 4 } & $(\mathrm{m} / \mathrm{min})$ & NF-MQL & MQL \\
\hline 1 & 220 & 0.04 & 0.07 \\
2 & 235 & 0.09 & 0.15 \\
3 & 250 & 0.13 & 0.23 \\
4 & 265 & 0.19 & 0.32 \\
5 & 280 & 0.24 & $\ldots$ \\
6 & 295 & 0.31 & $\cdots$ \\
\hline
\end{tabular}




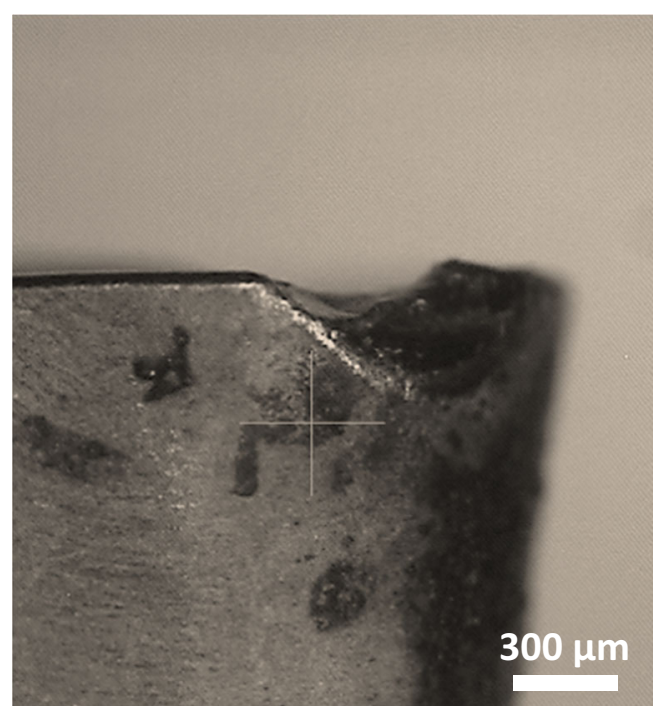

Fig. 2 Tool wear after experimentation at $0.30 \mathrm{~mm}$ (trial experimentation in dry environment)

Fig. 3 for both lubrication modes. Based on tool wear criteria (Fig. 3), the machining time was measured against flank wear criteria of $0.3 \mathrm{~mm}$. Further, $\mathrm{C}$ has been calculated as given in Table 5.

Using the values of " $\mathrm{C}$ " for each machining mode and $n=$ 0.5 for carbide cutting tools [40], we calculated the tool life. It is worthy to note from Fig. 3 is the evident escalation in wear with rising cutting speed. While the correct interpretation of the wear phenomenon science that elicits the upsurge in the tool will grant the growth process to be preferred suitably. As $V_{C}$ rises, plastic deformation starts enhancing heat production and friction in the first and second cutting zone, respectively. This condition elevated the temperature of the focused zone that causes the deteriorating of mechanical attributes of cutting insert and thus dwindling of the wear resistance occurs [41].

The nanofluid-based MQL system can potentially control temperature at the cutting zone. The conduction phenomenon
Table 5 The calculation for the values of $\mathrm{C}$

\begin{tabular}{llllr}
\hline Sr. & Machining Mode & $\begin{array}{l}\text { Cutting speed } V \\
(\mathrm{~m} / \mathrm{min})\end{array}$ & $\begin{array}{l}\text { Machining } \\
\text { time T(min) }\end{array}$ & $\mathrm{C}=$ \\
\hline 1 & MQL machining & 261.66 & 9.06 & 787.59 \\
2 & NFMQL machining & 292.85 & 13.11 & 1060.34 \\
\hline
\end{tabular}

is naturally present in all modes of cutting as tool makes connection with workpiece. The efficient penetration of nanoparticles in the cutting zone fabricates a layer on the surface [42]. The layer inherits low shearing strength, giving path for rapid conduction which ultimately lowers the temperature. In addition to the conduction, the phenomenon of convection helps in controlling the temperature [43]. The nanoparticles help in reducing sliding friction, temperature, and cutting force which improves the tool life.

Figure 4 illustrates the impact of no cooling and lubrication mechanisms to shield the cutting tool by sinking the temperature in various machining modes [43]. Therefore, in dry turning, natural convection heat transfer mechanism is responsible for the flow of heat from the hot workpiece/tool/chips exteriors to the environment [30]. However, in other turning modes, heat transfer is betrothed to ensure cooling action in the hot zones due to the forced convection mechanism [38]. Nevertheless, it is ignored in dry cutting mode [38]. The heat transfer rate is swayed by the smooth or rough surface condition of the hot temperature origin and the fluid flow attributes for example laminar and turbulent flow to cool and lubricate the tool [27]. As the heat flux density and transfer rate increase, the Reynolds number also increases because of the fluid velocity that boosts turbulent flow. Compared to MQL, the NF-MQL mode liaising with a cooling source $\left(\mathrm{SiO}_{2}\right)$ additional raised the heat transfer, as evinced in tool wear discussion. The key difference between these two modes is due to the temperature alterations in cooling abilities. During
Fig. 3 Tool Wear under different cutting environments

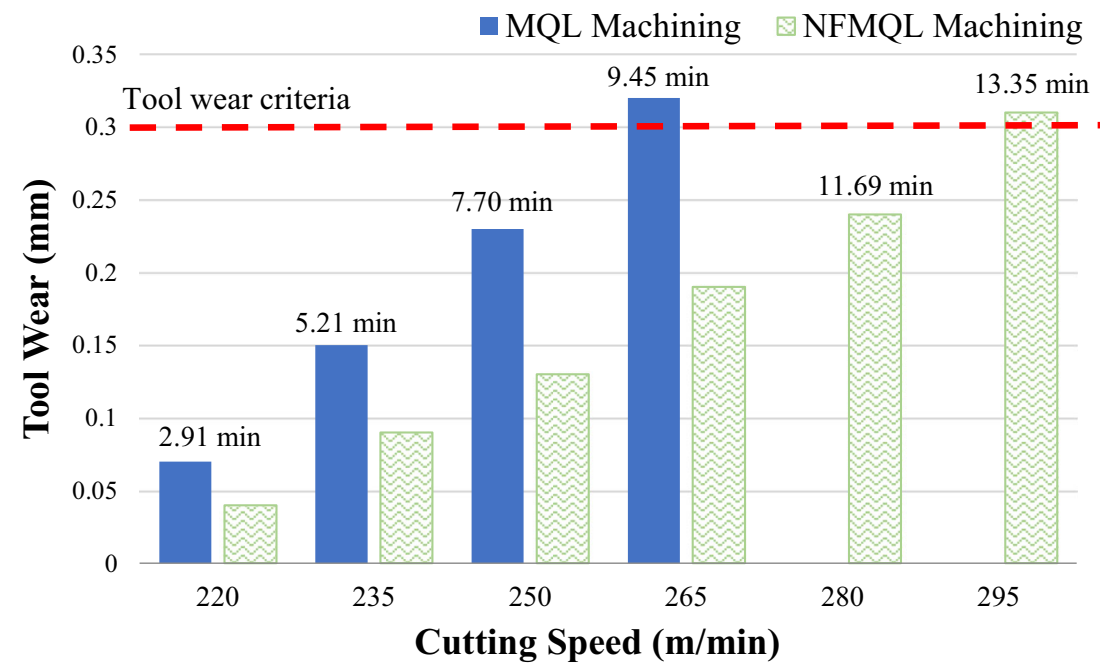


Fig. 4 Heat generation and transfer sources through various lubrication techniques in machining (copyrighted and used with permission) [43]

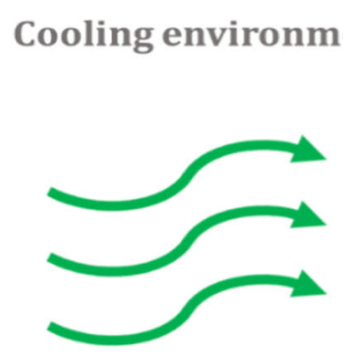

\section{Air-based}

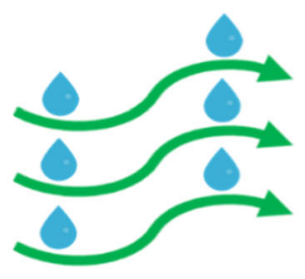

Water-based

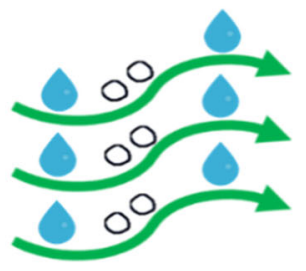

Water-SiO 2 -based

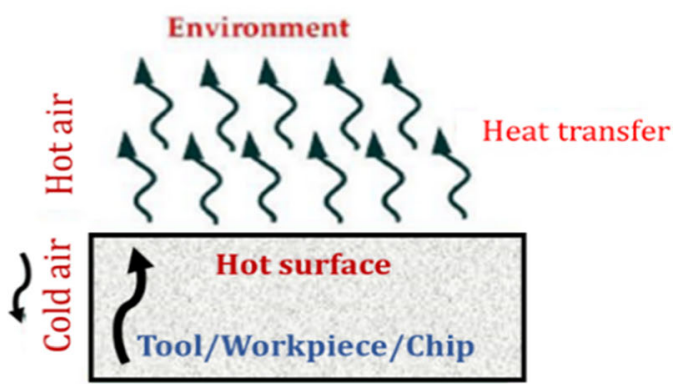

Dry machining

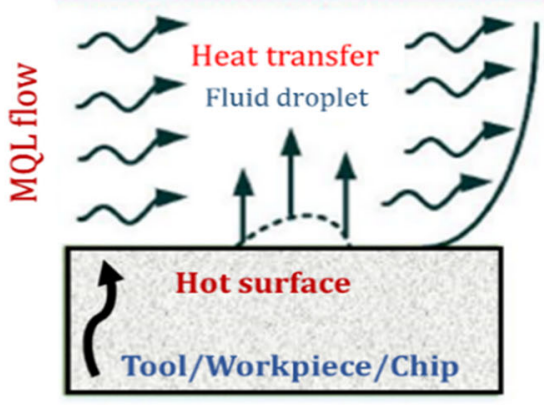

MQL-based machining

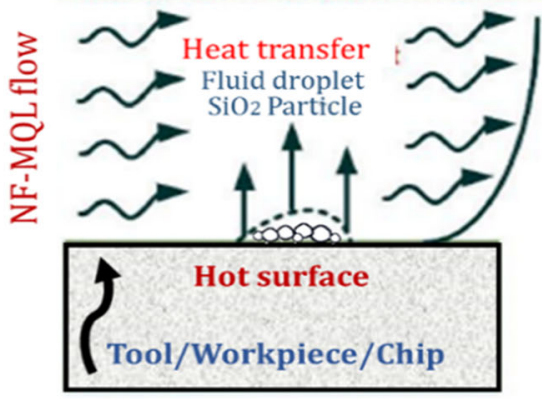

NF-MQL-based machining turning in both the lubricative conditions (MQL, NF-MQL), the water droplets strike the hot machined surface; the heat was immersed and dissipated off from the hot region through an evaporative act [31]. Therefore, the MQL/NF-MQL mode supports the cutting process in various behaviors in addition to hastening the heat transfer.

The microscopic images of the tool flank face after $10 \mathrm{~min}$ of turning under the espoused lubricating modes depict the occurrence of adhesion and the build-up-edge region at the tool flank face (see Fig. 5). These residues established as a result of the chip flowing at tool flank face that lean toward to force the solid nanoparticles of the lubrication (nanofluid) into the tool flank face depression intended to assist the chip breaking. A uniform abrasion of the flank face was found in all conditions without the creation of the wear notch irrespective the tested approaches as illustrated in the micrographs of Fig. 5. After 10 min of turning no chipping affected by the buildup-edge region, variability was observed on the worn cuttingedge even though the significant occurrence of adhered material. As tool wear is a collective consequence of plastic deformation, adhesion, abrasion, and diffusion among the workpiece-tool materials. The high produced temperatures regulate a severe cutting-edge worsening and the formation of the typical crater wear at flank face. The cratering phenomenon instigates with the adhesion of workpiece material on the tool flank face such as the build-up-edge region creation, tool matrix pauperization, and embrittlement. At some locations, the elimination of the adhered material initiated by the chip flowing leads to tire out the tool consequent in the crater wear creation. The maximum crater depth resembles the region of the maximum temperature alongside the tool creature the thermally activated diffusion process [41]. When machining HSLA steel, tool nose wear results to be precarious because of the high essential cutting forces. Normally, tool nose wear formation is ascribable to both the abrasion and adhesion onto the cutting edge which ultimately generates the chipping effect [41] which often leads to crack propagation because of forces [44]. These wear mechanisms which frequently overlap decisive a cutting edge dimensional loss resulting in geometrical variations of the machined workpiece [38]. 
Fig. 5 Flank wear microscopic analysis under $\mathbf{a} \mathrm{MQL}$, and $\mathbf{b} \mathrm{NF}$ MQL conditions
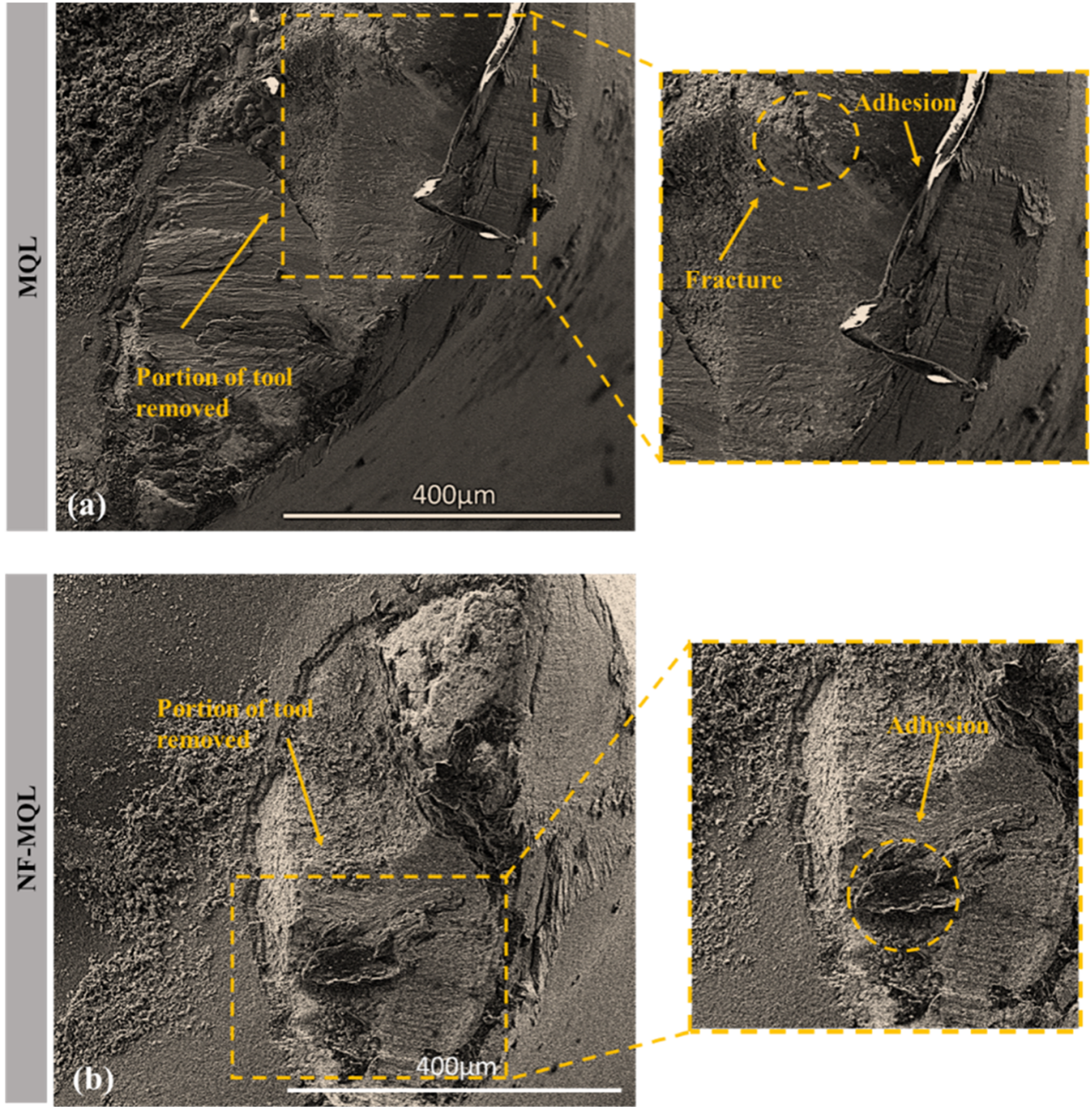

\subsection{Surface morphology analysis}

Rough surface phenomena produce uneven aberrations below and above the nominal surface line. The prestige of the machined surfaces is accountable for perilous targets in terms of product developed [41]. Figure 6(a-f) depicts that the finest surface quality was attained in NF-MQL mode, however, worst surface quality was obtained in MQL turning under severe conditions. It shows feed marks (marks of tool cutting action) and scratches (irregular interaction of outside element such as chips). Perfection in surface quality is anticipated by way of cooling and lubrication is used with machining fluid [45]. But, with the use of nanofluid, the enhancement in surface quality was noticeable higher. In the case of NF-MQL, nano-solid lubricants pierce well to the tool-workpiece and tool-chip interface. While the nano-additives evacuate the heat in a superior way from the cutting region by cumulative the thermal conductivity of machining fluid. This phenomenon is supported by the results of wear discussed already. Particularly in MQL machining, the wear and build-up-edge region on the machining tool were the clear and steady decline of these in NF-MQL turning which causes an auspicious impact on Ra. Some previous studies support it such as Yildirim et al. [45] observed that tool wear cutting temperature and forces were declined with nanofluid and ultimately surface quality improved. In a different study, Das et al. [10] examined that nanofluid offers lower Ra than other machining oils because nanofluid improved heat dissipation and cooling/ lubricating attributes [21].

With the suitable lubrication mode, the machining parameters are also essential to be selected prudently to attain better surface finish. Ra is a function of $F_{r}, D_{O C}$, and $V_{C}$, and an increment in $\mathrm{Ra}$ is estimated with the rise of $F_{r}$ and $V_{C}$ as shown in Fig. 6(a-f). Thus, high value of Ra occurs with high $F_{r}$ Fig. 6(a-f). In the current study, the minimum Ra was obtained under the lowest $F_{r}$ value $(0.10 \mathrm{~mm} / \mathrm{rev})$ and Ra increased with the increasing of $F_{r}$. Ra values of $0.1,0.15$, and $0.2 \mathrm{~mm} / \mathrm{rev}$ were increased $0.829,0.961$, and $1.229 \mu \mathrm{m}$, respectively, under MQL lubrication as compared to NFMQL. SR values of $0.1,0.15$, and $0.2 \mathrm{~mm} / \mathrm{rev}$ were also increased in NF-MQL showing 0.462, 0.737, and $1.194 \mu \mathrm{m}$, respectively. Similar trends in the literature found, revealed 
this situation $[45,46]$. Figure 6(a-f) demonstrated that Ra was low at the low $V_{C}$, however, from that forward it was amplified. As a result of the rise in Ra with step-up of $V_{C}$ (from $110 \mathrm{~m} / \mathrm{min}$ to $180 \mathrm{~m} / \mathrm{min}$ ) due to the inadequate thermal softening of the material at very high speed. It is also considered that the worn cutting insert deteriorated the surface finish because of earlier inflowing of wear process [46, 47].

The surface profile of machined parts taken at high magnification is represented in Fig. 7(a-f). This reflects the perceptible change in Ra due to the $F_{r}$ and $V_{C}$ on the surfaces of machined parts. The higher $F_{r}$ and $V_{C}$ value has thus led to increasing tool movement along the length of the workpiece. From the surface images, it has been observed that a higher $\mathrm{Fr}$ value leads to larger distances between peaks and vice versa. The elongation effect caused by deformation of material with larger grooves depth results at higher feed values. This combined effect results in an increase in Ra. MQL machining particularly through carbide machining tools reveals an efficacious part in sinking wear and friction. It is done because of the very thin layer on the tool-chip mating zones and ultimately decreases Ra (see Fig. 8). During MQL turning process cutting fluid was detained on the machined side and stimulated the plastic fluidity at the backside of chips, consequently creating a significant impact on the machining process. However, nano-cutting fluids work efficiently in coherence with carbide cutting tools [48]. Seeing that under traditional cooling environments, $\mathrm{SiO}_{2}$ with low thermal shock resistance can cause unattractive conditions, however, in this study $\mathrm{H}_{2} \mathrm{O}-\mathrm{SiO}_{2}$-based NF-MQL along with MQL demonstrated superb accomplishment in terms of Ra. It is assumed that tribological enrichment mechanisms such as rolling effect, polishing effect, protect film, and mending effect contributes to this situation [38]. The apparent physical phenomena of these mechanisms with $\mathrm{MQL}$ and $\mathrm{SiO}_{2}$ waterbased NF-MQL machining process is illustrated Fig. 8.

The Fig. 8 establishes the functionality of lubrication. It helps to understand the counter-science of tool wear aided through nanofluids. The protective layer, mending, rolling, and polishing effects are directly linked with tool life and workpiece surface quality. In NF-MQL turning, through the mending influence (in Fig. 8 (NF-MQL)), employment of $\mathrm{SiO}_{2}$ nanoparticles in micro-channels in tool-workpiece interaction area, carry the force and evade the contact of friction pairs that promotes sinking friction and wear. Polishing phenomena on the machined surface emerged due to the $\mathrm{SiO}_{2}$ particles that grind mounds under the influence of high
Fig. 6 The microstructural surface texture of machined samples for a-c MQL, and d-f NF-MQL conditions

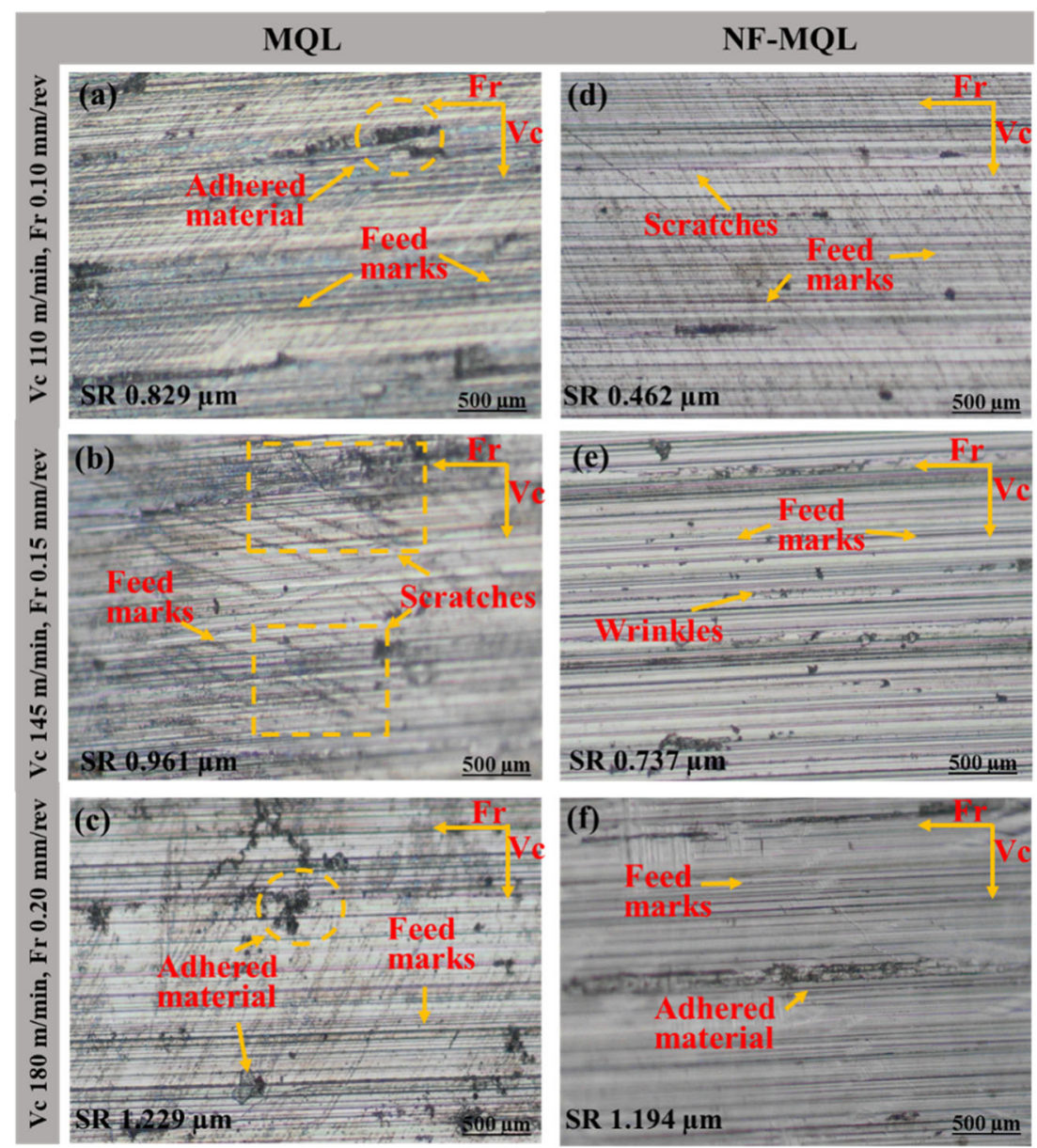


Fig. 7 SEM images of machined surfaces for a-c MQL, and $\mathbf{d}-\mathbf{f}$ NF-MQL conditions

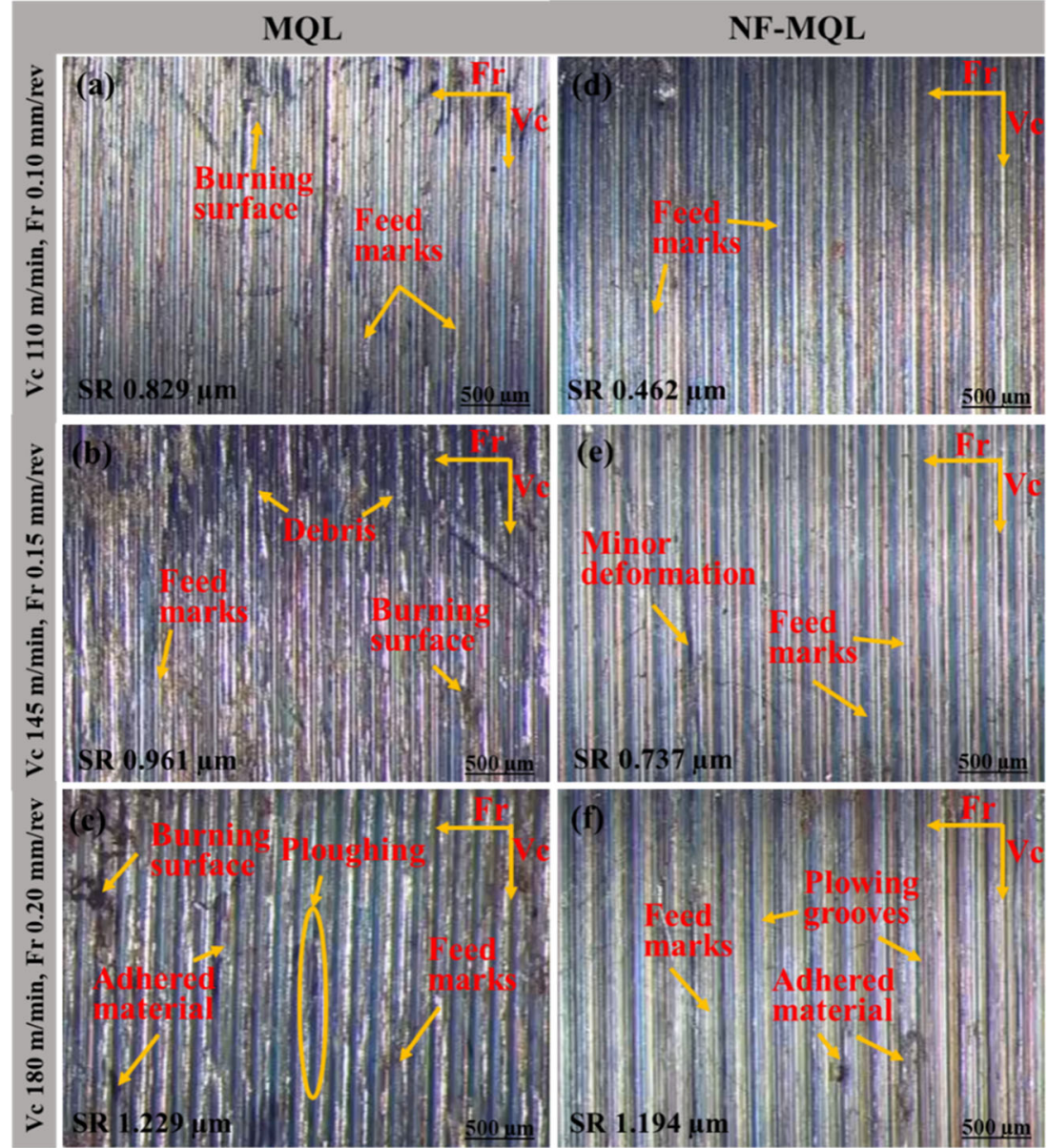

pressure and rotational speed during machining. The particles served like the rolling bearing (rolling effect), thus decreasing the contact zone and friction between the tool-workpiece [48]. While in protective film influence, $\mathrm{SiO}_{2}$ nanoparticles in a sliding manner interacted with the tool-workpiece interactive surfaces and construct a protective layer that decreased physical-interaction between the rubbing surfaces to eradicate wear [38]. All the impacts of $\mathrm{SiO}_{2}$ nanoparticles lessen $\mathrm{Ra}$ of machined surfaces. In a comparison of $\mathrm{H}_{2} \mathrm{O}-\mathrm{MQL}$ mode, the better surface is achieved in $\mathrm{H}_{2} \mathrm{O}$ NF-MQL mode as shown in
Fig. 7(a-f). Under NF-MQL mode, nanoparticles adhere on the machined surface which causes lower friction between workpiece and tool during machining which is resulted in better surface finish.

Figure 9 shows three-dimensional images of the surface after turning with at $V_{C} 110$ to $180 \mathrm{~m} / \mathrm{min}, F_{r} 0.10$ to $0.20 \mathrm{~mm} / \mathrm{rev}$ and at both lubrication methods. Feed traces were observed on the surface, which is typical of turning. The surface and subsurface properties highly depend on surface topography. Therefore, promising surface topography

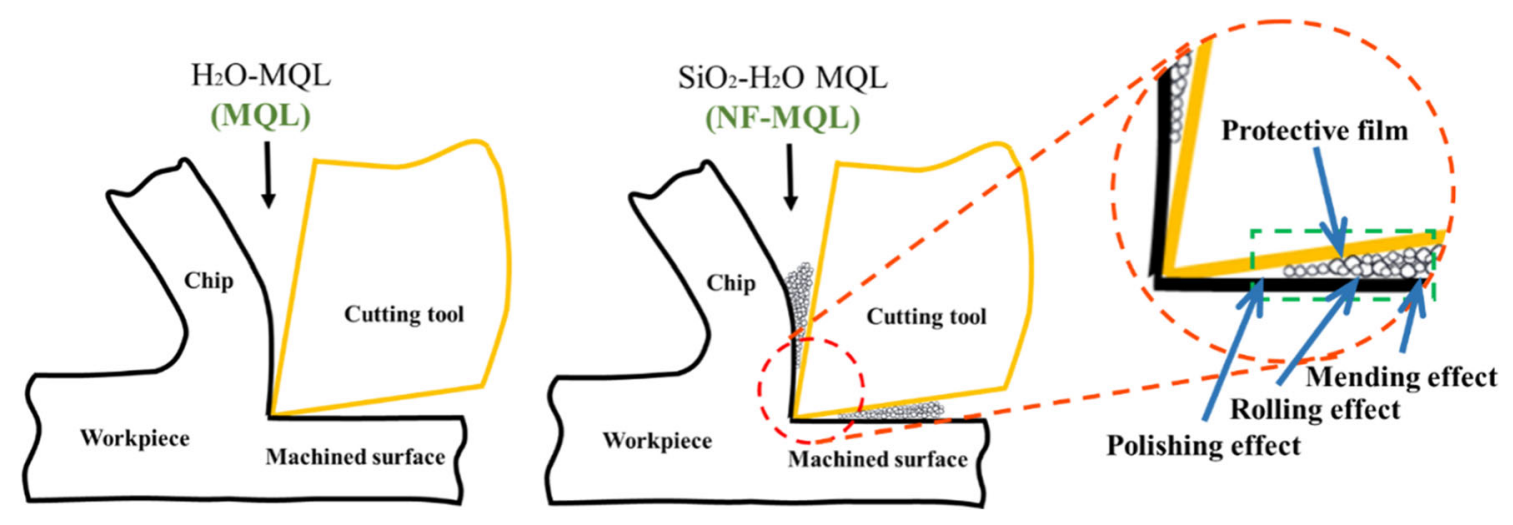

Fig. 8 Lubrication phenomenon for heat generation and surface quality enhancement in machining 
Fig. 9 Surface topographic images of HSLA steel samples processed under lubrication conditions: a, $\mathbf{d} V_{c} 110 \mathrm{~m} / \mathrm{min}, F_{r}$ $0.10 \mathrm{~mm} / \mathrm{rev}, \mathbf{b}, \mathbf{e} V_{c} 145 \mathrm{~m} / \mathrm{min}$, $F_{r} 0.15 \mathrm{~mm} / \mathrm{rev}, \mathbf{c}, \mathbf{f} V_{c} 180 \mathrm{~m} /$ $\min , F_{r} 0.20 \mathrm{~mm} / \mathrm{rev}$
MQL
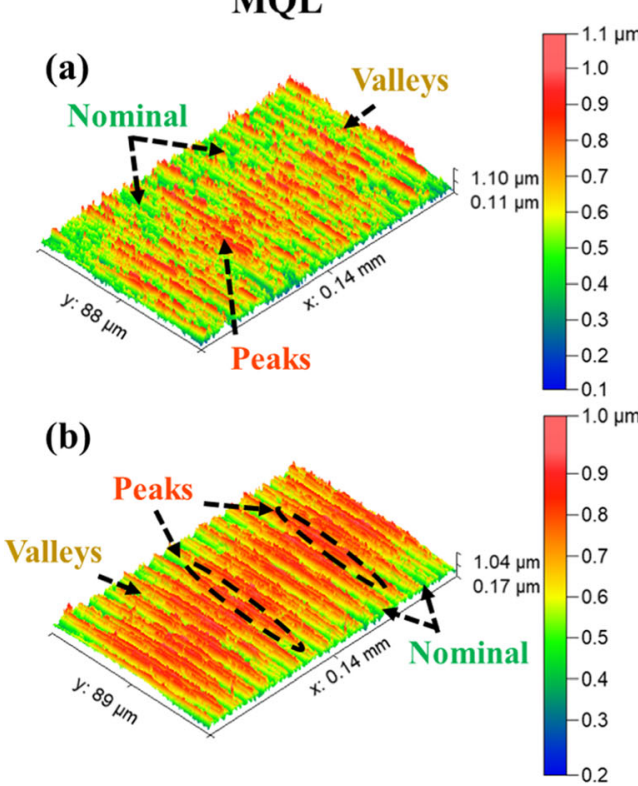

(c)

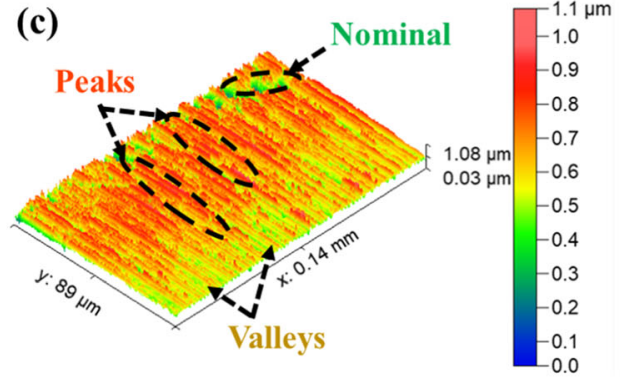

NF-MOL
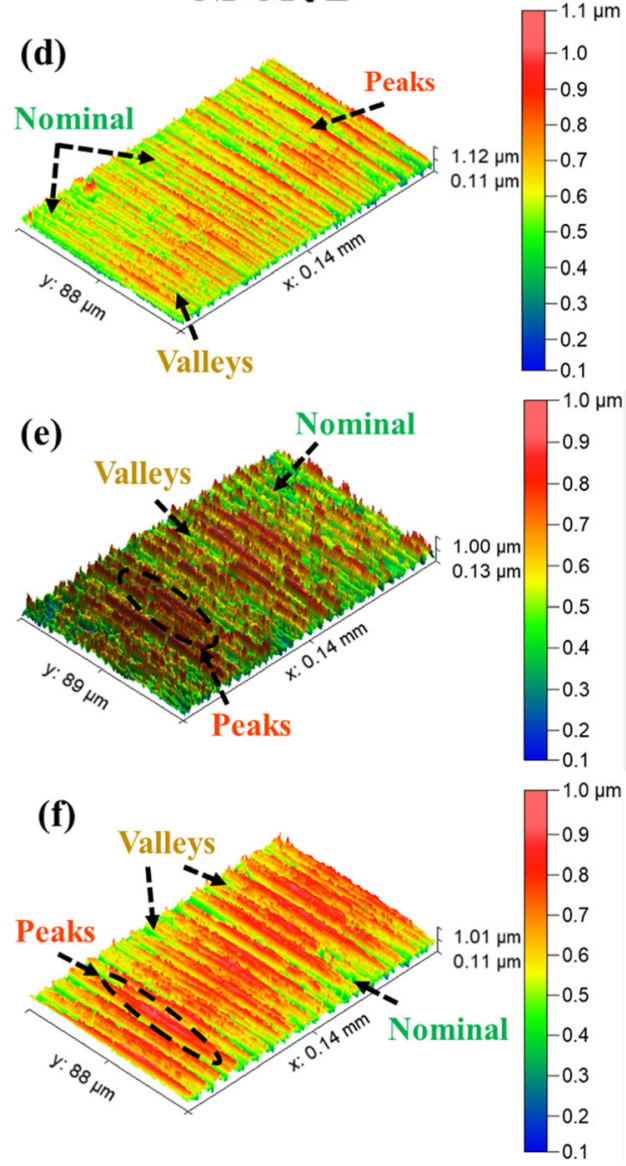

can result in superior surface quality. After MQL machining, the surface had irregular pits, narrow, and high peaks as shown in Fig. 9(a-c). The peaks and valleys are highlighted in different colors. After NF-MQL machining, the surface irregular features such as peaks and deep pits, narrow and high ridges are reduced as compared to MQL generated surface as displayed in Fig. 9(d-f). It can be concluded that at low $V_{C}$, low $F_{r}$, and NF-MQL lubrication conditions, the surface produced was observed to be better as evident from Fig. 9(a-f) in the terms of the height of ridges, and other surface anomalies. The deformations on the surface are the result of plastic deformation of the material through the turning process.

\subsection{Parametric effects analysis}

\subsubsection{D surface plots for surface roughness}

The 3D surface plots (Fig. 10) show the effects of process parameters $\left(V_{C}, F_{r}\right.$ and $\left.D_{O C}\right)$ on Ra during NF-MQL and MQL machining. Figure 10(a) illustrates the combined effect of $V_{C}$ and $F_{r}$ on Ra. The value of $\mathrm{Ra}$ is increased with the increase in $V_{C}$ and the same thing is observed for the feed-in MQL mode, but the effect of $F_{r}$ is more significant than the $V_{C}$. The same behavior has been observed during NF-MQL mode as shown in Fig. 10(d). While Fig. 10(b) and Fig. 10(e) depict the combined effect of $V_{C}$ and $D_{O C}$ on Ra under both conditions. From Fig. 10(b), it is clear, by increasing $D_{O C}$ from $0.30 \mathrm{~mm}$ to $0.60 \mathrm{~mm}$, the value of $\mathrm{Ra}$ is decreased. But at higher $D_{O C}$, the value of $R a$ has been increased. The lowest value of Ra is achieved at $D_{O C}$ of $0.60 \mathrm{~mm}$ and $V_{C}$ of $110 \mathrm{~m} /$ min during NF-MQL mode as indicated by Fig. 10(e). Impacts of $F_{r}$ and $D_{O C}$ on Ra for MQL and NF-MQL conditions is presented in Fig. 10(c) and Fig. 10(f), respectively. By increasing $F_{r}$, the value of $\mathrm{Ra}$ is also increased. A similar effect has been observed in case of $D_{O C}$ but $F_{r}$ effects more significantly on surface roughness than $D_{O C}$ under both cutting modes. Similar findings are achieved under NFMQL conditions by DX et al. [49]. During machining of HSLA steel, less jagged chips attained under NF-MQL turning that is desirable in machining than MQL turning. Localized adiabatic shear bands formation is the reason of jagged chips. It also resulted in increased variability and Surface roughness because of the increase in cutting forces. From Fig. 10(d-f), it has been perceived that NF-MQL turning gives superior surface integrity, however, the worst surface is attained using dry turning (which was carried out in trail experimentation as a baseline to visualize improvement). During dry turning, high friction, and tool wear was experienced. Similar considerations are 
Fig. $103 \mathrm{D}$ surface plots for Ra under a-c MQL, d-f NF-MQL lubrication condition
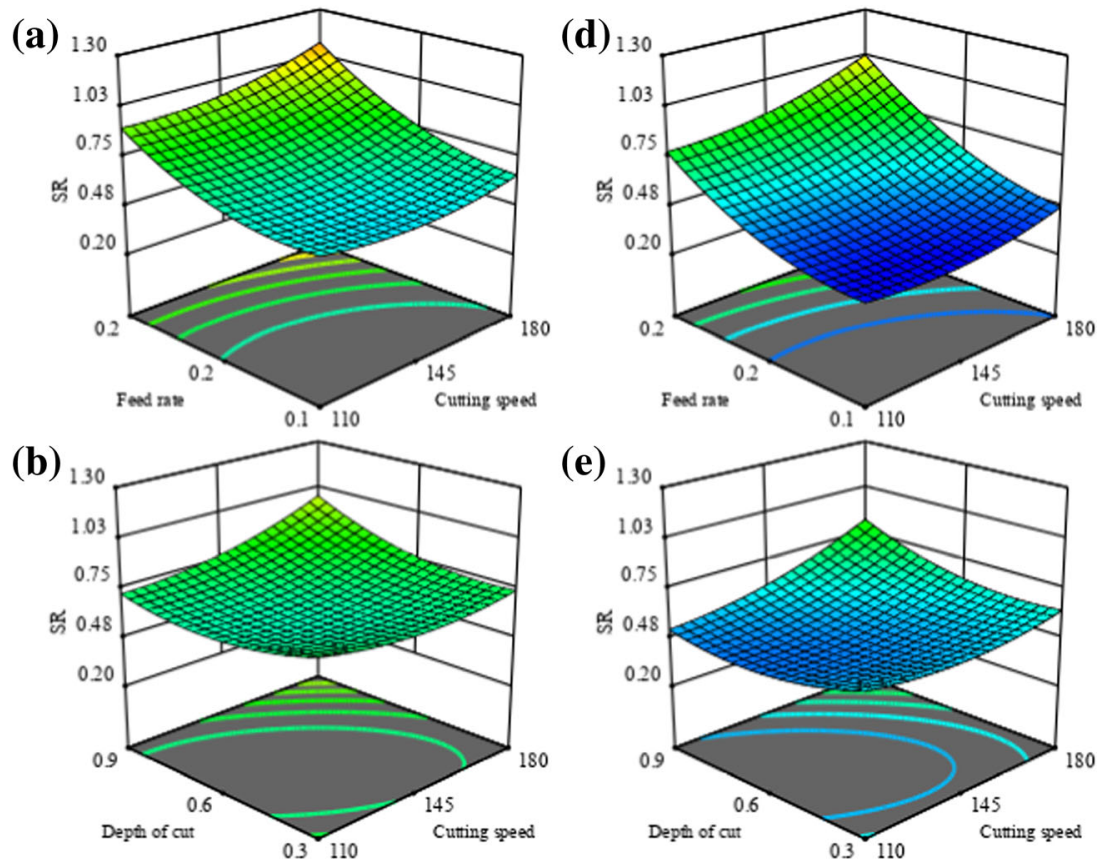

(e)

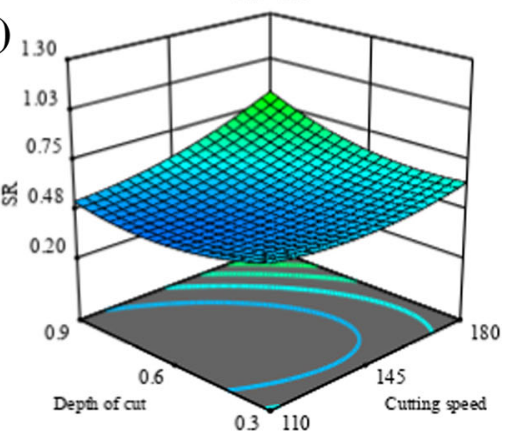

(c)

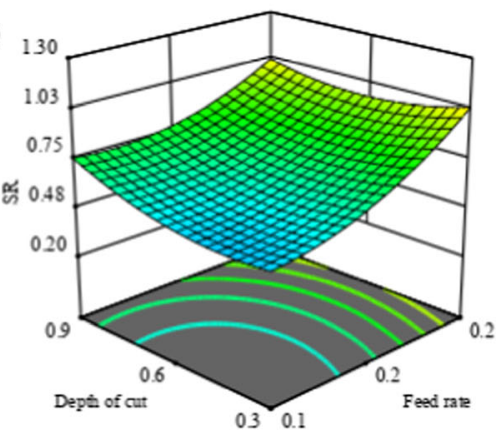

(f)

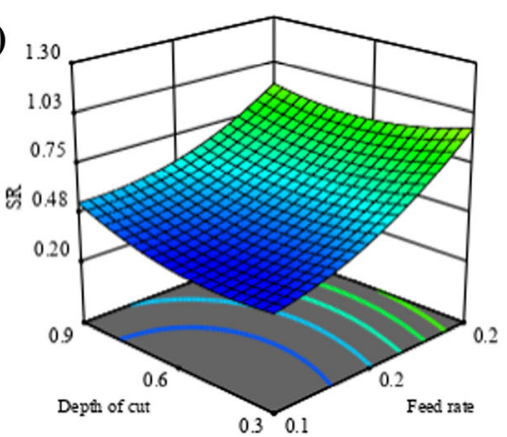

endorsed in the literature [50]. Ra values declined significantly up to $\sim 30 \%$ using NF-MQL turning than MQL. The efficiency of the lubrication method is revealed in the enhancements of surface quality. In case of NF-MQL turning, $\mathrm{H}_{2} \mathrm{O}$ $\mathrm{SiO}_{2}$ based nanofluid confiscated the frictional heat from the cutting zone. Consequently, less heat is generated in the cutting process due to the lubri-film surroundings than the MQL environment which ultimately diminished tool wear and rarer surface defects. Besides, it is vastly possibility that slackly attached chips cause the adhesion to the machined surface. In any case, the efficient cooling ability of nanofluid claim that the water-based lubrication stops the micro-chip remains to stick to the machined surface and enhance the Ra [8]. Azam et al. [51] found SR of HSLA steel around $1 \mu \mathrm{m}$, however, current research produced promising results through $\mathrm{H}_{2} \mathrm{O}-$ $\mathrm{SiO}_{2}$ based nanofluid MQL.

\subsubsection{D surface plots for material removal rate}

Figure 11(a) and Fig. 11(d) depict the effects of $V_{C}$ and $F_{r}$ on MRR under MQL and NF-MQL modes, respectively. For
MQL, maximum MRR is obtained at the high level of both process parameters by keeping $D_{O C}$ constant $0.6 \mathrm{~mm}$ whereas similar trends are obtained for NFMQL mode. But the high value of MRR $\left(\sim 25,000 \mathrm{~mm}^{3} /\right.$ $\mathrm{min}$ ) has achieved in case of NF-MQL. Response plots for $V_{C}$ and $D_{O C}$ are presented in Fig. 11(b) and Fig. 11(e). Variation in $D_{O C}$ has a significant effect on MRR as compare to $V_{C}$ and $F_{r}$ [52]. Highest MRR is achieved at a high level of both $V_{C}$ and $D_{O C}$ in case of both lubrication modes. Figure 11(c) and Fig. 11(f) depict the effect of $F_{r}$ and $D_{O C}$ on MRR for both conditions. Increase in $F_{r}$ and $\mathrm{D}_{\mathrm{OC}}$ resulted in MRR for both cases but the high value of MRR $\left(\sim 27,000 \mathrm{~mm}^{3} / \mathrm{min}\right)$ has obtained in case of NFMQL mode. So, for achieving high MRR, high $\mathrm{D}_{\mathrm{OC}}$ is in favor under NF-MQL mode of machining. Das [53] worked on the parametric optimization of HSLA 4340 during turning. It has been concluded that $F_{r}(70.22 \%)$ is the most important factor for good surface finish followed by $V_{C}(21.66 \%)$ and $D_{O C}(6.21 \%)$. However, current research has produced comparable results with NF-MQL lubrication system. 
Fig. 11 3D surface plots for MRR under a-c MQL, d-f NFMQL lubrication condition

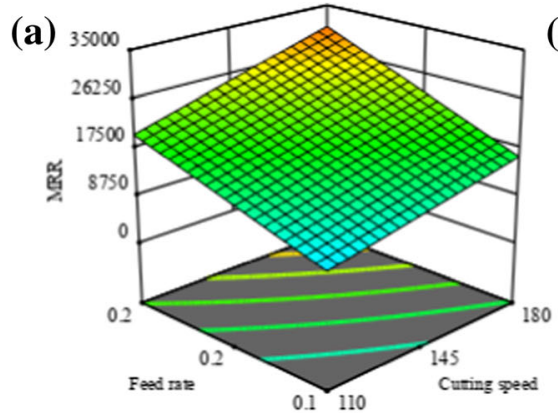

(b)

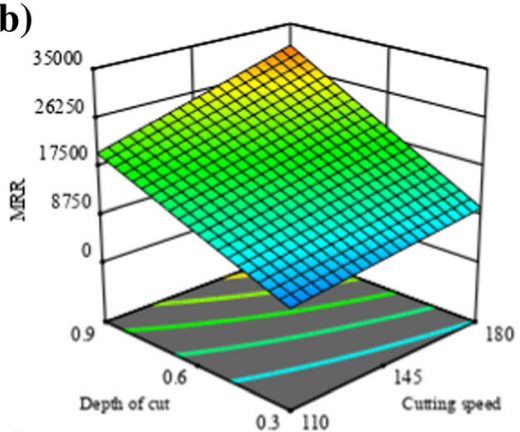

(c)

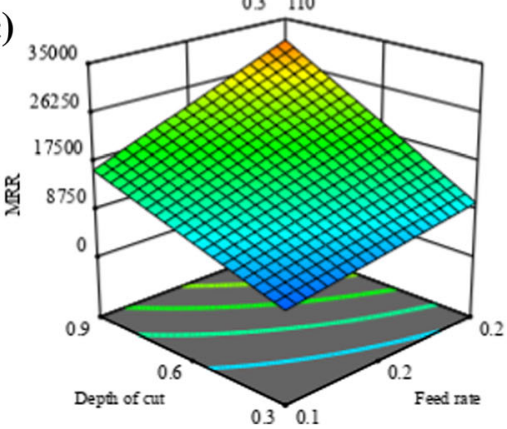

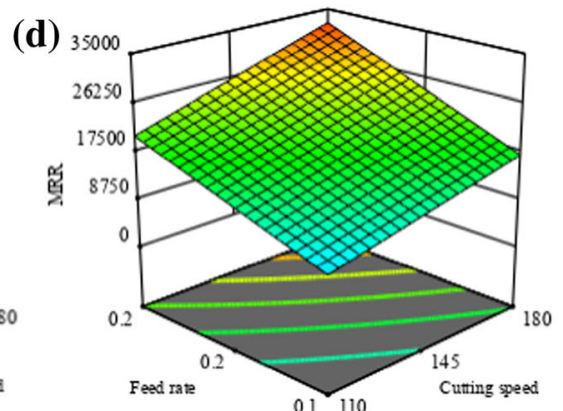

(e)

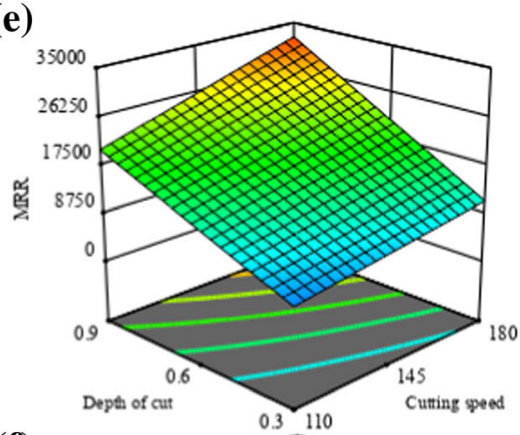

(f)

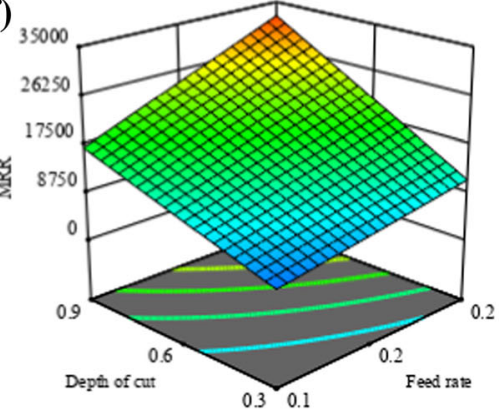

\subsection{Machinability comparative analysis}

The discussion in the earlier sections highlights that NF-MQL mode reduces Ra. From Fig. 12, it is cleared that Ra value improves in the case of NFMQL mode by $28.34 \%$. However, a very minute effect of $5.09 \%$ is observed in the case of MRR as shown in Fig. 13. The prime reason behind the fact is lubrication modes significantly affect tool life and surface characteristics, and slightly influence material removal. The cutting action in both cases is similar, however, surface quality is improved using modified lubrication technology. As evident in literature, Haq et al. [43] endorsed the fact of slight influence on MRR by NF-MQL in comparison to water-based MQL. However, NF-MQL improved surface features substantially.

Cutting tools were observed during machining under two cutting environments as shown in Fig. 3 and found that more wear was observed during MQL turning in comparison with NF-MQL turning. $\mathrm{SiO}_{2}-\mathrm{H}_{2} \mathrm{O}$ nanofluid has been used in NFMQL machining. Lower the value of tool wear causes high tool life. The average tool life values were analyzed graphically as shown in Fig. 14. It was noticed that more tool life was obtained during NF-MQL machining. The tool life obtained during NF-MQL machining was 1.81 times that of MQL machining. During NF-MQL machining, both the crater and flank wear were significantly reduced. The main reason behind this is convection, conductivity, and wettability due to adequate cooling and lubricative properties of the nanofluid [11]. The tool maintains its toughness for an increased period. Thus, the flank wear amount will be minimal in comparison to the other cutting conditions of machining [8]. Therefore, these are the reasons behind the improvement of tool life during NFMQL turning.

\subsection{Parametric significance analysis and empirical modeling}

Best fit models for MQL and NFMQL are selected based on test statics and results of experimentation. Quadratic model is chosen as the best fit model for Ra and Linear model is selected for MRR under both machining conditions prescribed by model fit summary. The significance of factors is indicated by analysis of variance (ANOVA) in Table 6 and Table 7 for Ra and MRR, correspondingly. From ANOVA table, it results 


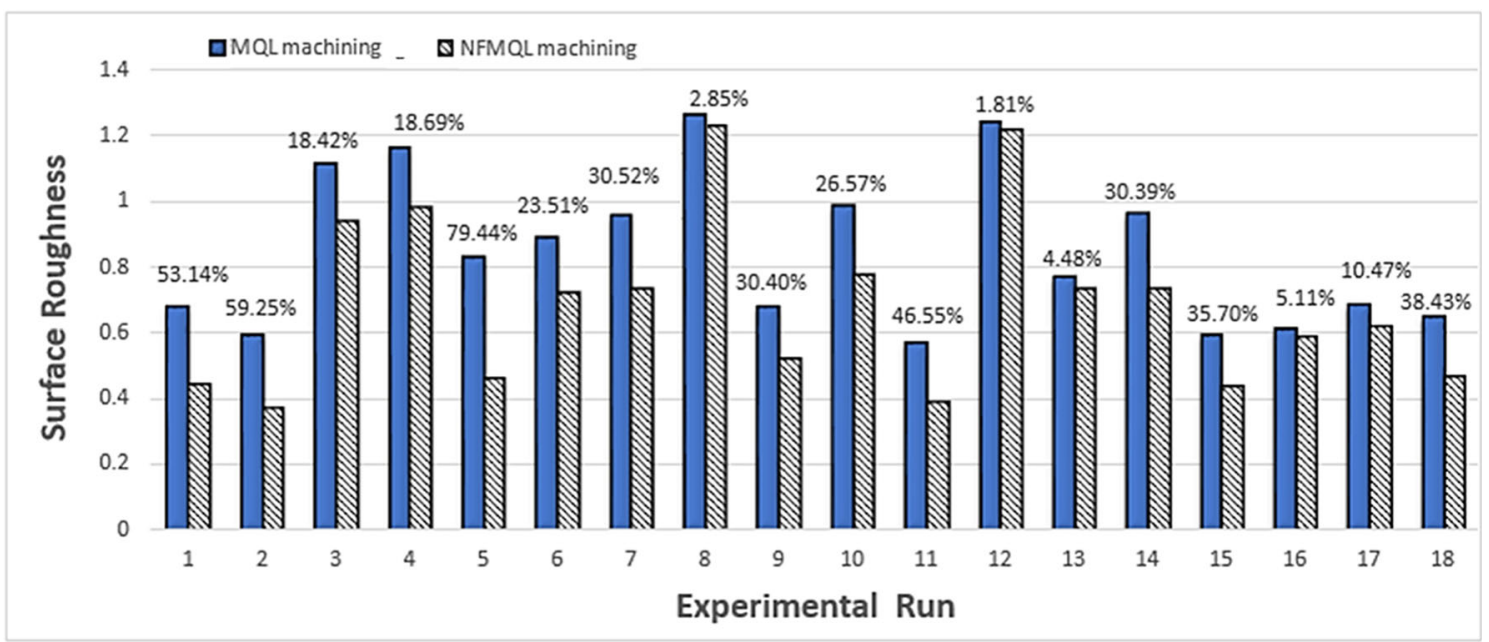

Fig. 12 Percentage improvement of SR

that factors including $V_{C}, F_{r}, D_{O C}, M O L$, interaction $\left(V_{C} \times\right.$ $\left.F_{r}\right),\left(V_{C} \times D_{O C}\right),\left(F_{r} \times D_{O C}\right),\left(F_{r} \times M O L\right)$, and square terms $V_{C}^{2}, F_{r}^{2}, D_{O C}{ }^{2}$ are significant process parameters in determining the magnitude of Ra of HSLA steel and factors including $V_{C}, F_{r}, D_{O C}, M O L$, and interaction $\left(V_{C} \times F_{r}\right),\left(V_{C} \times D_{O C}\right)$, $\left(F_{r} \times D_{O C}\right)$ are significant factors for MRR of HSLA steel that is indicated by their $p$ values. Adequacy of models is indicated by the value of $R^{2}$ which is closer to unity i.e. 0.9618 and 0.9863 for SR and MRR, respectively. Also, the values of $\mathrm{R}^{2}$ adjusted and $\mathrm{R}^{2}$ predicted for $\mathrm{Ra}$ are 0.9392 and 0.8986 , respectively, which shows acceptable process variation. The value coefficient of variance (C.V) is $8.2023 \%$ which show the precision and reliability of experiments run for Ra. In the case of MRR, the values of $\mathrm{R}^{2}$ adjusted and $\mathrm{R}^{2}$ predicted are 0.9809 and 0.9616 whereas the value of C.V is $8.20 \%$. The mathematical models for SR are described by Eq. (4) and Eq. (5) whereas, for MRR, these are defined by Eq. (6) and Eq. (7).

$$
\begin{aligned}
\mathrm{Ra}_{\mathrm{MQL}}= & 2.80-0.02 \times C_{S}-9.45 \times F_{r}-1.34 \times D_{O C} \\
& +0.02 \times C_{S} \times F_{r}+0.01 C_{S} \times D_{O C}-3.7 \\
& \times F_{r} \times D_{O C}+4.95 \times 10^{-5} \times C_{S}^{2}+39.97 \\
& \times F_{r}^{2}+0.90 \times D_{O C}^{2}
\end{aligned}
$$

$$
\begin{aligned}
\mathrm{Ra}_{\mathrm{NF}-\mathrm{MQL}}= & 2.41-0.02 \times C_{S}-8.40 \times F_{r}-1.40 \times D_{O C} \\
& +0.02 \times C_{S} \times F_{r}+0.01 \times C_{S} \\
& \times D_{O C}-3.7 \times F_{r} \times D_{O C}+4.95 \times 10^{-5} \\
& \times C_{S}^{2}+39.97 \times F_{r}^{2}+0.90 \times D_{O C}^{2}
\end{aligned}
$$

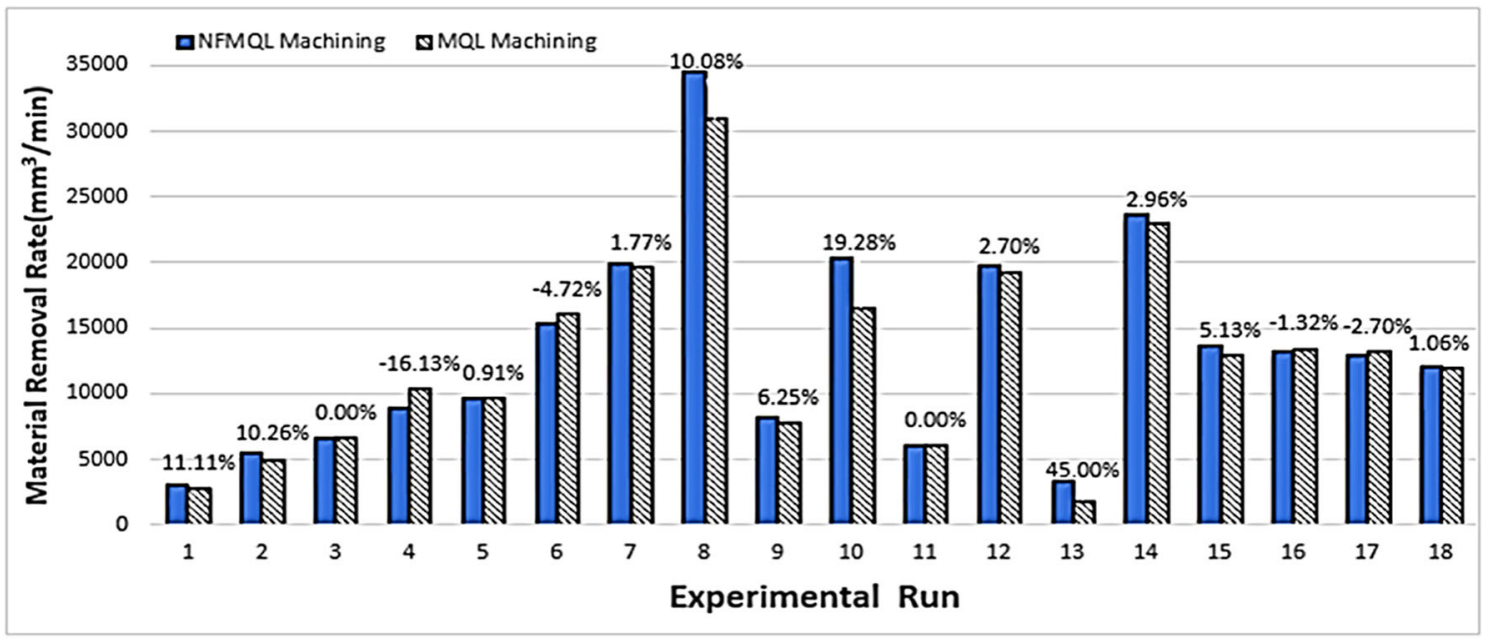

Fig. 13 Percentage improvement of MRR 
Fig. 14 Tool Life comparison under different cutting environments

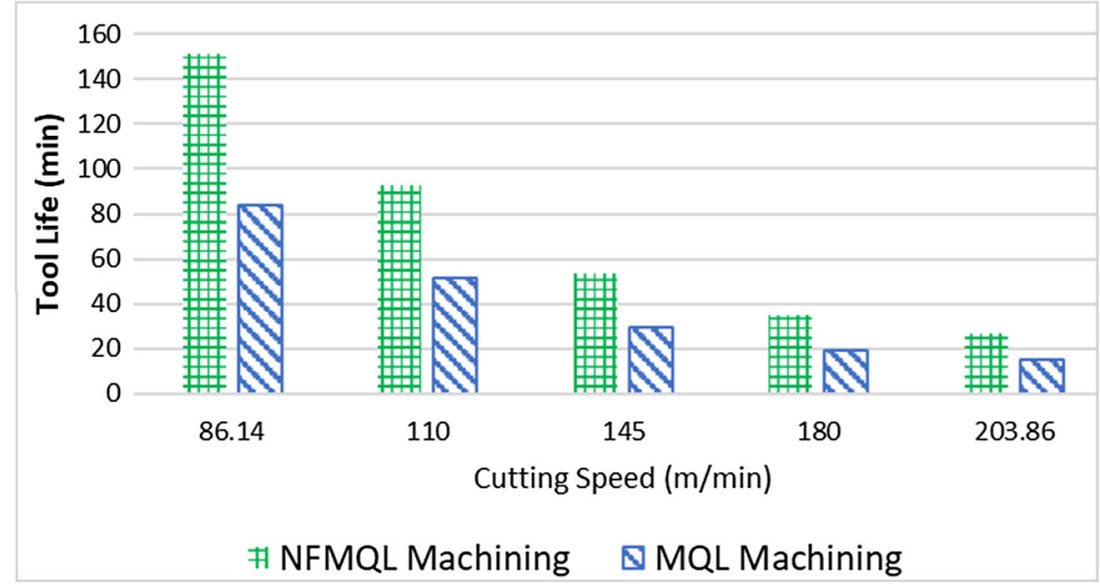

F NFMQL Machining $\triangle M Q L$ Machining

$$
\begin{aligned}
\mathrm{MRR}_{\mathrm{MQL}}= & 15980.66-97.16 \times C_{S}-90428.27 \\
& \times F_{r}-26121.45 \times D_{O C}+534.92 \times C_{S} \\
& \times F_{r}+161.46 \times C_{S} \times D_{O C}-1.58 \times 10^{-5} \\
& \times F_{r} \times D_{O C}
\end{aligned}
$$

\begin{tabular}{|c|c|c|c|c|c|c|}
\hline Source & SS & Df & MS & F Value & $\mathrm{p}$ value & Source \\
\hline Model & 2.18 & 13 & 0.17 & 42.56 & $<0.0001$ & significant \\
\hline$V_{C}$ & 0.14 & 1 & 0.14 & 34.43 & $<0.0001$ & \\
\hline$F_{r}$ & 1.23 & 1 & 1.23 & 312.67 & $<0.0001$ & \\
\hline$D_{O C}$ & 0.04 & 1 & 0.04 & 10.40 & 0.0039 & \\
\hline$M O L$ & 0.22 & 1 & 0.22 & 55.19 & $<0.0001$ & \\
\hline$V_{C} \times F_{r}$ & 0.03 & 1 & 0.03 & 6.86 & 0.0157 & \\
\hline$V_{C} \times D_{O C}$ & 0.08 & 1 & 0.08 & 20.17 & 0.0002 & \\
\hline$V_{C} \times M O L$ & 0.01 & 1 & 0.01 & 1.35 & 0.2578 & \\
\hline$F_{r} \times D_{O C}$ & 0.05 & 1 & 0.05 & 12.50 & 0.0019 & \\
\hline$F_{r} \times M O L$ & 0.02 & 1 & 0.02 & 4.80 & 0.0393 & \\
\hline$D_{O C} \times M O L$ & 0.00 & 1 & 0.00 & 0.51 & 0.4848 & \\
\hline$V_{C}^{2}$ & 0.09 & 1 & 0.09 & 23.63 & $<0.0001$ & \\
\hline$F_{r}^{2}$ & 0.25 & 1 & 0.25 & 64.07 & $<0.0001$ & \\
\hline$D_{O C}{ }^{2}$ & 0.17 & 1 & 0.17 & 42.39 & $<0.0001$ & \\
\hline Residual & 0.09 & 22 & 0.00 & & & \\
\hline Lack of fit & 0.0580 & 16 & 0.0036 & 0.7600 & 0.6927 & not significant \\
\hline Pure error & 0.0290 & 6 & 0.0048 & & & \\
\hline \multirow[t]{5}{*}{ Cor total } & 2.2700 & 35 & & & & \\
\hline & Std. Dev. & 0.06 & $\mathrm{R}^{2}$ & & 0.96 & \\
\hline & Mean & 0.76 & Adj $R^{2}$ & & 0.93 & \\
\hline & C.V. $\%$ & 8.20 & Pred $R^{2}$ & & 0.89 & \\
\hline & PRESS & 0.23 & Adq precision & & 22.22 & \\
\hline
\end{tabular}

Table 6 ANOVA results for Ra 
Table 7 ANOVA results for MRR

\begin{tabular}{lllllrl}
\hline Source & SS & Df & MS & F Value & p value & \\
\hline Model & $2,019,893,953.52$ & 10 & $201,989,395.35$ & 180.53 & $<0.0001$ & significant \\
$V_{C}$ & $253,747,854.25$ & 1 & $253,747,854.25$ & 226.79 & $<0.0001$ & \\
$F_{r}$ & $487,965,340.58$ & 1 & $487,965,340.58$ & 436.13 & $<0.0001$ & \\
$D_{O C}$ & $1,122,393,336.41$ & 1 & $1,122,393,336.41$ & 1003.17 & $<0.0001$ & \\
$M O L$ & $2,905,442.75$ & 1 & $2,905,442.75$ & 2.60 & 0.1196 & \\
$V_{C} \times F_{r}$ & $14,021,331.10$ & 1 & $14,021,331.10$ & 12.53 & 0.0016 & \\
$V_{C} \times D_{O C}$ & $45,990,863.48$ & 1 & $45,990,863.48$ & 41.11 & $<0.0001$ & \\
$V_{C} \times M O L$ & $1,700,784.28$ & 1 & $1,700,784.28$ & 1.52 & 0.2291 & \\
$F_{r} \times D_{O C}$ & $90,661,688.95$ & 1 & $90,661,688.95$ & 81.03 & $<0.0001$ & \\
$F_{r} \times M O L$ & $324,988.99$ & 1 & $324,988.99$ & 0.29 & 0.5947 & \\
$D_{O C} \times M O L$ & $182,322.72$ & 1 & $182,322.72$ & 0.16 & 0.6899 & \\
Residual & $27,971,210.69$ & 25 & $1,118,848.43$ & & & \\
Lack of fit & $25,211,255.23$ & 19 & $1,326,908.17$ & 2.88 & 0.0969 & not significant \\
Pure error & $2,759,955.45$ & 6 & $459,992.58$ & & & \\
Cor total & $2,047,865,164.20$ & 35 & & & & \\
Std. Dev. & 1057.76 & & $\mathrm{R}^{2}$ & & 0.98 & \\
Mean & $12,903.62$ & & Adj $\mathrm{R}^{2}$ & & & \\
C.V. \% & 8.20 & & Pred R $\mathrm{R}^{2}$ & & & \\
PRESS & $78,603,253.04$ & & Adequate precision & & & \\
\hline
\end{tabular}

\subsection{Experimental validation}

Validation of models has been conducted by performing the three confirmatory tests. The values of process parameters on which the validation experiments performed were within the designed range. Percentage error related to predicted and actual values is computed using Eq. 8 [20] as shown in Table 8 . The percentage error is below $5 \%$ for both responses which confirm the soundness of developed models.

$\%$ age of error $=\left|\frac{\text { actual value- } \text { predicted value }}{\text { predicted value }}\right| * 100$

\subsection{One-step sustainability}

One-step sustainable machining approach is feasible through NF-MQL, where $V_{C}, F_{r}$ and $D_{O C}$ are relating to roughing functions, while the workpiece surface quality is analogous to that of finished machining. Through it, better outcomes can be attained with fewer resources as well as less cycle time. Additionally, because of low tool wear and better surface quality, lower energy consumption, sustainable liquid, and related costs, the use of $\mathrm{SiO}_{2}$ is recommended over MQL.

Table 8 Model validation data

\begin{tabular}{|c|c|c|c|c|c|c|c|c|}
\hline \multirow{4}{*}{ Sr. No. } & \multicolumn{3}{|c|}{ Input Parameters } & \multicolumn{5}{|l|}{ Responses } \\
\hline & \multirow[t]{2}{*}{$V_{C}$} & \multirow[t]{2}{*}{$F_{r}$} & \multirow[t]{2}{*}{$D_{O C}$} & & \multicolumn{2}{|c|}{ Surface Roughness } & \multicolumn{2}{|l|}{ MRR } \\
\hline & & & & & \multicolumn{2}{|l|}{$(\mu \mathrm{m})$} & \multicolumn{2}{|c|}{$\left(\mathrm{mm}^{3} / \mathrm{min}\right)$} \\
\hline & $\begin{array}{l}\mathrm{m} / \\
\mathrm{min}\end{array}$ & $\begin{array}{l}\mathrm{mm} / \\
\mathrm{rev}\end{array}$ & $\mathrm{mm}$ & & MQL & NFMQL & MQL & NFMQL \\
\hline \multirow[t]{3}{*}{1} & 130 & 0.12 & 0.4 & Actual & 0.581 & 0.412 & 6112.3 & 6537.57 \\
\hline & & & & predicted & 0.584112 & 0.39644 & 6407.79 & 6522.252 \\
\hline & & & & $\%$ error & $0.53 \%$ & $3.92 \%$ & $4.61 \%$ & $0.23 \%$ \\
\hline \multirow[t]{3}{*}{2} & 160 & 0.18 & 0.7 & Actual & 0.873 & 0.747 & $19,422.9$ & $20,116.6$ \\
\hline & & & & predicted & 0.87717 & 0.75953 & 19,358 & $20,325.43$ \\
\hline & & & & $\%$ error & $0.48 \%$ & $4.46 \%$ & $0.34 \%$ & $1.03 \%$ \\
\hline \multirow[t]{3}{*}{3} & 170 & 0.14 & 0.5 & Actual & 0.685 & 0.565 & $11,277.1$ & $12,232.8$ \\
\hline & & & & predicted & 0.664822 & 0.524425 & $11,306.6$ & $12,133.18$ \\
\hline & & & & $\%$ error & $3.04 \%$ & $3.90 \%$ & $0.26 \%$ & $0.82 \%$ \\
\hline
\end{tabular}


Table 9 Measured responses at optimal parametric conditions

\begin{tabular}{|c|c|c|c|c|c|c|c|c|c|c|}
\hline \multirow{2}{*}{$\frac{\mathrm{MOL}}{\mathrm{MQL}}$} & \multicolumn{2}{|c|}{ Optimum input variables } & \multicolumn{4}{|c|}{ Responses } & \multirow{2}{*}{$\begin{array}{l}\text { Average trials values } \\
18,860.6\end{array}$} & \multirow{2}{*}{$\begin{array}{l}\text { Standard deviation } \\
0.6548\end{array}$} & \multirow{2}{*}{$\begin{array}{l}\text { Predicted values } \\
18,759.76\end{array}$} & \multirow{2}{*}{$\begin{array}{l}\text { Error \% } \\
0.53\end{array}$} \\
\hline & $V_{C}$ & 143.42 & MRR & $18,760.6$ & $18,759.7$ & 18,759 & & & & \\
\hline & $\begin{array}{l}F_{r} \\
D_{O C}\end{array}$ & $\begin{array}{l}0.1574 \\
0.8616\end{array}$ & $\mathrm{Ra}$ & 0.77 & 0.75 & 0.76 & 0.76 & 0.0081 & 0.78 & 2.56 \\
\hline \multirow[t]{2}{*}{ NF-MQL } & $V_{C}$ & 145.22 & MRR & 20,466 & 20,467 & 20,466 & $20,466.33$ & 0.4741 & 20,662 & 0.94 \\
\hline & $\begin{array}{l}F_{r} \\
D_{O C}\end{array}$ & $\begin{array}{l}0.1570 \\
0.8999\end{array}$ & $\mathrm{Ra}$ & 0.63 & 0.65 & 0.67 & 0.65 & 0.0163 & 0.64 & 1.56 \\
\hline
\end{tabular}

Aim of this research is to produce better quality parts at a higher production rate by improving surface finish. The performance measures directly associated with these two sustainable production attributes include $\mathrm{Ra}$ and MRR. Thus, to achieve sustainability, all these responses essential to be stated in term of a single objective function as shown in Eq. (9) [54].

Multiobjective optimization is the best way to acquire an optimal combination of parameters for contradictory responses [55]. Desirability is an effective way to simultaneously optimize the responses $[56,57]$. This technique is employed to allocate the desirability range from 0 to 1 (minimum to maximum); which depends on the envisioned responses, incase to minimize or maximize the targeted response. Firstly, desirability function is established, after that, objective function, as well as compound function, are determined that is weighted geometric mean for all responses values [34].

Optimization targets $=\left\{\begin{array}{c}\text { Minimize Surface Roughness } \\ \text { Maximize Material Removal Rate }\end{array}\right\}$
The optimized values of process parameters and performance measures for turning of HSLA Steel (30CrMnSiA) have been presented in Table 9. Both responses (Ra \& MRR) are simultaneously optimized by selecting the input parameters such as $V_{C}$ of $143.4 \mathrm{~m} /$ $\min , F_{r}$ of $0.157 \mathrm{~mm} / \mathrm{min}, D_{O C}$ of $0.86 \mathrm{~mm}$, and MQL mode of lubrication (Fig. 15a), while in case of NF-MQL mode of lubrication (Fig. 15b); $V_{C}$ of $145.2 \mathrm{~m} / \mathrm{min}, F_{r}$ of $0.16 \mathrm{~mm} / \mathrm{min}$, and $D_{O C}$ of 0.89 . The optimization shows that for MQL turning, the minimum value of $\mathrm{Ra}(0.78 \mu \mathrm{m})$ and maximum MRR $\left(18,860 \mathrm{~mm}^{3} / \mathrm{min}\right)$ have been achieved with $52.83 \%$ and $52.17 \%$ desirability, respectively. The combined desirability is found to be rationally good, i.e., $52.50 \%$ which shows the capability of the proposed model. The optimization for NF-MQL turning establishes a minimum value of $\mathrm{Ra}$ $(0.64 \mu \mathrm{m})$ and maximum MRR $\left(20,662 \mathrm{~mm}^{3} / \mathrm{min}\right)$ have been attained with $68.48 \%$ and $57.75 \%$ desirability, respectively. The combined desirability $(62.89 \%)$ is found to be reasonably good which demonstrations the fitness of the proposed model. Confirmatory trials results of optimized solutions for both
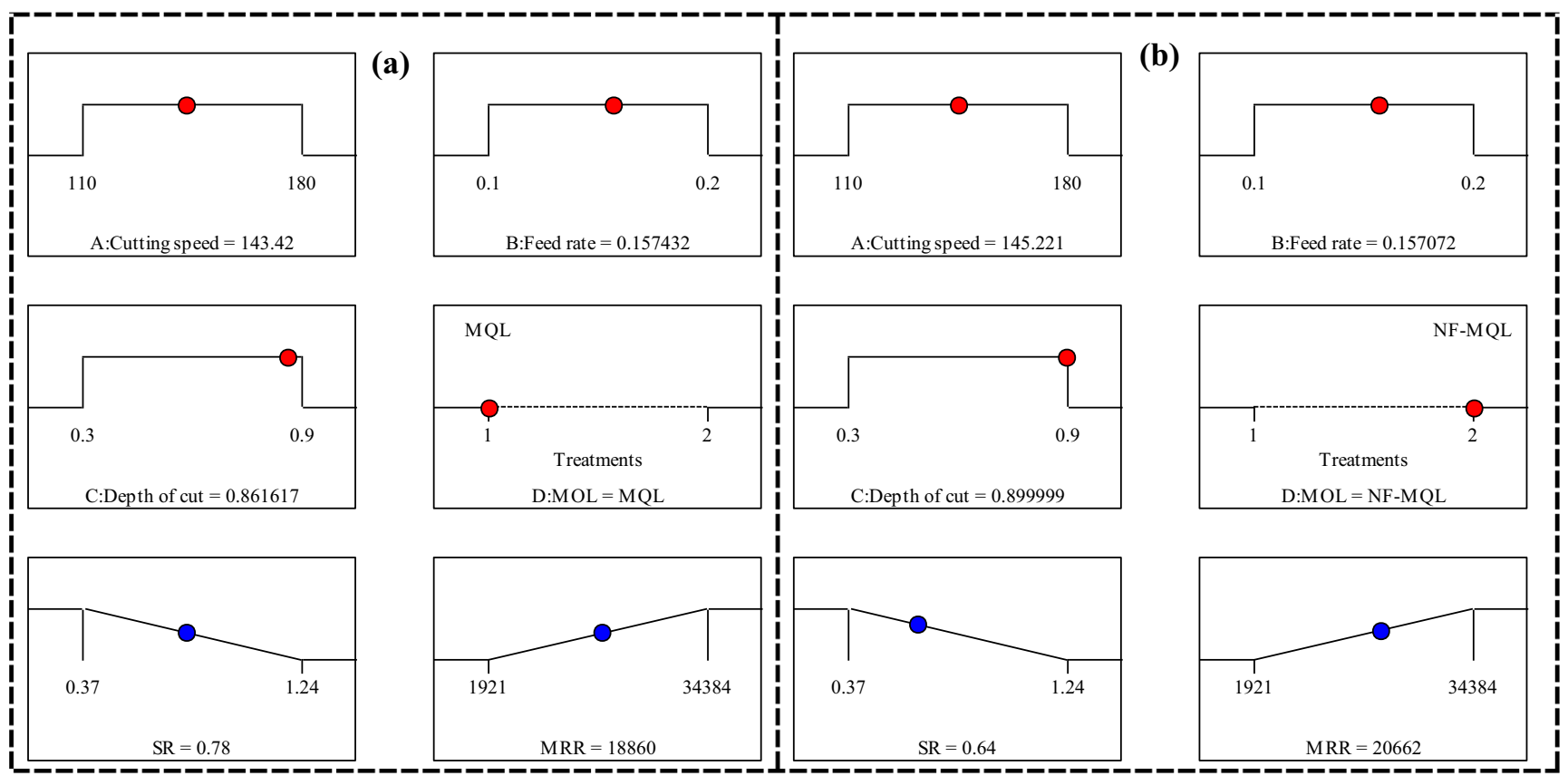

Fig. 15 Desirability Plots for MQL (a) and NF-MQL turning (b) 
lubrication conditions endorse the adequacy of predicted models as an error is less than $3 \%$ (Table 9).

\section{Conclusion}

This research examined in detail the impacts of MQL and NFMQL on surface quality and MRR in the machining of HSLA Steel. To obtain a parametric evaluation the effects of different critical parameters: $V_{C}, F_{r}$ and $D_{O C}$ on Ra and MRR were carefully analyzed by using RSM. Following conclusions was drawn from the current research:

- The use of nanofluid MQL condition reveals better performances with a major improvement in surface quality (28.34\%) and MRR (5.09\%) when comparing to MQL alone.

- MRR is highly influenced by $D_{O C}$. In NF-MQL turning, through the mending influence, employment of $\mathrm{SiO}_{2}$ nanoparticles in micro-channels in tool-workpiece interaction area, carry the force, and evade the contact of friction pairs that promotes sinking friction and wear.

- The tool life obtained during NF-MQL machining was 1.81 times longer that of MQL machining due to its toughness for an increased period. During NF-MQL machining, both the crater and flank wear were significantly reduced because of the convection, conductivity, and wettability attributable due to adequate cooling and lubricative properties of the nanofluid.

- One-step sustainability technique, process variables used for roughing conditions are analogous to attain surface comparable to finished machining without compromising process efficiency, which is feasible through optimal settings under NF-MQL.

- Optimal settings for improvement in both responses have been achieved at $V_{C}$ of $145.2 \mathrm{~m} / \mathrm{min}, F_{r}$ of $0.16 \mathrm{~mm} / \mathrm{rev}$, $D_{O C}$ of $0.90 \mathrm{~mm}$, and NF-MQL is selected as the mode of lubrication with the desirability of $62.89 \%$.

- The use of $\mathrm{SiO}_{2}$ is recommended over MQL because of low tool wear and better surface quality, lower energy consumption, sustainable liquid, and related costs.

The results of this study are considered paramount important for machinists in determining the optimal settings of input parameters as well as sustainable machining environment to achieve better surface quality and productivity of HSLA steel machined parts, therefore, enabling zero-emission manufacturing for the industry.

Authors contributions Conceptualization, H. Javid and M. Jahanzaib; methodology, H. Javid and M. Jawad; software, M. Jawad and H. Javid; validation, H. Javid; formal analysis, H. Javid, M. Jawad; investigation, H. Javid, and M. Jahanzaib; resources, S. Hussain; data curation, H. Javid; writing - original draft preparation, M. Jawad, M.U. Farooq and M.A. Ali; writing - review and editing, M.U. Farooq, M.A. Ali and C.I. Pruncu; visualization, M.U. Farooq and M.A. Ali; supervision, M. Jahanzaib; project administration, H. Javid and S. Hussain; funding acquisition, C.I.Pruncu. All authors have read and agreed to the published version of the manuscript..

Data availability All necessary data is already present in the study.

\section{Declarations}

Consent to publish The authors provide their consent to publish this work in The International Journal of Advanced Manufacturing Technology.

Competing interests The authors declare no competing interests.

Open Access This article is licensed under a Creative Commons Attribution 4.0 International License, which permits use, sharing, adaptation, distribution and reproduction in any medium or format, as long as you give appropriate credit to the original author(s) and the source, provide a link to the Creative Commons licence, and indicate if changes were made. The images or other third party material in this article are included in the article's Creative Commons licence, unless indicated otherwise in a credit line to the material. If material is not included in the article's Creative Commons licence and your intended use is not permitted by statutory regulation or exceeds the permitted use, you will need to obtain permission directly from the copyright holder. To view a copy of this licence, visit http://creativecommons.org/licenses/by/4.0/.

\section{References}

1. Panda A, Das SR, Dhupal D (2018) Hard turning of HSLA steel with coated ceramic inserts: an assessment, modelling, optimisation and cost analysis. Int J Automot Mech Eng 15:5890-5913

2. Krolczyk GM, Krolczyk JB, Maruda RW, Legutko S, Tomaszewski M (2016) Metrological changes in surface morphology of high-strength steels in manufacturing processes. Measurement 88:176-185. https://doi.org/10.1016/j.measurement. 2016.03.055

3. Gupta M, Kumar S (2015) Investigation of surface roughness and MRR for turning of UD-GFRP using PCA and Taguchi method. Int J Eng Sci Technol 18:70-81

4. Nieslony P, Krolczyk GM, Wojciechowski S, Chudy R, Zak K, Maruda RW (2018) Surface quality and topographic inspection of variable compliance part after precise turning. Appl Surf Sci 434: 91-101. https://doi.org/10.1016/j.apsusc.2017.10.158

5. Davoodi B, Tazehkandi AH (2014) Experimental investigation and optimization of cutting parameters in dry and wet machining of aluminum alloy 5083 in order to remove cutting fluid. J Clean Prod 68:234-242

6. Sarıkaya M, Y1lmaz V, Güllü A (2016) Analysis of cutting parameters and cooling/lubrication methods for sustainable machining in turning of Haynes 25 superalloy. J Clean Prod 133:172-181

7. Zhang Y, Li C, Jia D, Zhang D, Zhang X (2015) Experimental evaluation of MoS2 nanoparticles in jet MQL grinding with different types of vegetable oil as base oil. J Clean Prod 87:930-940

8. Sayuti M, Sarhan AA, Salem F (2014) Novel uses of SiO2 nanolubrication system in hard turning process of hardened steel 
AISI4140 for less tool wear, surface roughness and oil consumption. J Clean Prod 67:265-276

9. Kumar R, Choudhury AR, Sahoo AK, Panda A, Malakar A (2020) Machinability investigation on novel Incoloy 330 super alloy using coconut oil based SiO2 Nano fluid. Int J Integ Eng 12:145-160

10. Das A, Das SR, Patel SK, Biswal BB (2020) Effect of MQL and nanofluid on the machinability aspects of hardened alloy steel. Mach Sci Technol 24:291-320

11. Bai X, Li C, Dong L, Y in Q (2019) Experimental evaluation of the lubrication performances of different nanofluids for minimum quantity lubrication (MQL) in milling Ti-6Al-4V. Int J Adv Manuf Technol 101:2621-2632

12. Sharma AK, Tiwari AK, Dixit AR, Singh RK (2017) Investigation into performance of $\mathrm{SiO} 2$ nanoparticle based cutting fluid in machining process. Materials Today: Proceedings 4:133-141

13. Amrita M, Srikant RR, Sitaramaraju AV (2014) Performance evaluation of nanographite-based cutting fluid in machining process. Mater Manuf Process 29:600-605

14. Zhang X, Li C, Zhang Y, Jia D, Li B, Wang Y et al (2016) Performances of $\mathrm{Al} 2 \mathrm{O} 3 / \mathrm{SiC}$ hybrid nanofluids in minimumquantity lubrication grinding. Int J Adv Manuf Technol 86:34273441

15. Sharma VS, Singh G, Sørby K (2015) A review on minimum quantity lubrication for machining processes. Mater Manuf Process 30: 935-953

16. Eltaggaz A, Said Z, Deiab I (2020) An integrated numerical study for using minimum quantity lubrication (MQL) when machining austempered ductile iron (ADI). Int J Interact Des Manuf 14:747758

17. Masoudi S, Vafadar A, Hadad M, Jafarian F (2018) Experimental investigation into the effects of nozzle position, workpiece hardness, and tool type in MQL turning of AISI 1045 steel. Mater Manuf Process 33:1011-1019

18. Su Y, He N, Li L, Iqbal A, Xiao MH, Xu S et al (2007) Refrigerated cooling air cutting of difficult-to-cut materials. Int J Mach Tools Manuf 47:927-933

19. Sharma VS, Dhiman S, Sehgal R, Sharma SK (2008) Estimation of cutting forces and surface roughness for hard turning using neural networks. J Intell Manuf 19:473-483

20. Ali MA, Ishfaq K, Raza MH, Farooq MU, Mufti NA, Pruncu CI (2020) Mechanical characterization of aged AA2026-AA2026 overcast joints fabricated by squeeze casting. Int J Adv Manuf Technol 107:3277-3297. https://doi.org/10.1007/s00170-02005242-9

21. Mao C, Huang Y, Zhou X, Gan H, Zhang J, Zhou Z (2014) The tribological properties of nanofluid used in minimum quantity lubrication grinding. Int J Adv Manuf Technol 71:1221-1228

22. Jeevan TP, Jayaram SR (2018) Performance evaluation of jatropha and pongamia oil based environmentally friendly cutting fluids for turning AA 6061. Adv Tribol 2425619. https://doi.org/10.1155/ $2018 / 2425619$

23. Khan AM, Jamil M, Haq AU, Hussain S, Meng L, He N (2019) Sustainable machining. Modeling and optimization of temperature and surface roughness in the milling of AISI D2 steel. Ind Lubr Tribol 71:267-277. https://doi.org/10.1108/ILT-11-2017-0322

24. Gangil B, Kothiyal P, Kumar S (2016) Experimental investigation of machining process parameters in conventional turning of Al7075 on MRR using response surface methodology. AIP Conf Proc 1728:020631. https://doi.org/10.1063/1.4946682

25. Abbas AT, Alata M, Ragab AE, El Rayes MM, El Danaf EA (2017) Prediction model of cutting parameters for turning high strength steel grade-H: comparative study of regression model versus ANFIS. Adv Mater Sci Eng 2017:2759020. https://doi.org/10. $1155 / 2017 / 2759020$
26. Jha SK, Singh S, Kumar SR (2012) Experimental Analysis of CNC Turning using Taguchi Method. Proc. of Int. Conf. on Advances in Mechanical Engineering, Dehli, India 3:91-5

27. Sayuti M, Sarhan AA, Tanaka T, Hamdi M, Saito Y (2013) Cutting force reduction and surface quality improvement in machining of aerospace duralumin AL-2017-T4 using carbon onion nanolubrication system. Int J Adv Manuf Technol 65:1493-1500

28. Nowak P, Kucharska K, Kamiński M (2019) Ecological and health effects of lubricant oils emitted into the environment. Int J Environ Res Public Health 16:3002

29. Jia D, Li C, Zhang Y, Zhang D, Zhang X (2016) Experimental research on the influence of the jet parameters of minimum quantity lubrication on the lubricating property of Ni-based alloy grinding. Int J Adv Manuf Technol 82:617-630

30. Rafati M, Hamidi AA, Niaser MS (2012) Application of nanofluids in computer cooling systems (heat transfer performance of nanofluids). Appl Therm Eng 45:9-14

31. Shah TR, Ali HM, Janjua MM (2020) On aqua-based silica (SiO2water) nanocoolant: convective thermal potential and experimental precision evaluation in aluminum tube radiator. Nanomaterials 10: 1736

32. Sardarabadi M, Passandideh-Fard M, Heris SZ (2014) Experimental investigation of the effects of silica/water nanofluid on PV/T (photovoltaic thermal units). Energy 66:264-272

33. Coromant S (2010) Metal cutting technology-technical guide. SandvikCoromant, Sweden

34. Ishfaq K, Farooq MU, Anwar S, Ali MA, Ahmad S, El-Sherbeeny MA (2021) A comprehensive investigation of geometrical accuracy errors during WEDM of Al6061-7.5\% SiC composite. Mater Manuf Process 36:362-372. https://doi.org/10.1080/10426914. 2020.1832683

35. Khanafer K, Eltaggaz A, Deiab I, Agarwal H, Abdul-latif A (2020) Toward sustainable micro-drilling of Inconel 718 superalloy using MQL-Nanofluid. Int J Adv Manuf Technol 107:3459-3469. https:// doi.org/10.1007/s00170-020-05112-4

36. Eltaggaz A, Deiab I (2019) Comparison of between direct and peck drilling for large aspect ratio in Ti-6Al-4V alloy. Int J Adv Manuf Technol 102:2797-2805. https://doi.org/10.1007/s00170-01903314-z

37. Krolczyk GM, Nieslony P, Legutko S (2015) Determination of tool life and research wear during duplex stainless steel turning. ArchivCivMechEng 15:347-354. https://doi.org/10.1016/j.acme. 2014.05.001

38. Gupta MK, Song Q, Liu Z, Sarikaya M, Jamil M, Mia M et al (2020) Experimental characterisation of the performance of hybrid cryo-lubrication assisted turning of Ti-6Al-4V alloy. Tribol Int 153:106582

39. Kovac P, Gostimirovic M, Rodic D, Savkovic B (2019) Using the temperature method for the prediction of tool life in sustainable production. Measurement 133:320-327

40. Kalpakjian S, Schmid SR (2017) Musa H. Manufacturing Engineering and Technology Sixth Edition, Prentice Hall

41. Agrawal C, Wadhwa J, Pitroda A, Pruncu CI, Sarikaya M, Khanna N (2020) Comprehensive analysis of tool wear, tool life, surface roughness, costing and carbon emissions in turning Ti-6Al-4V titanium alloy: cryogenic versus wet machining. Tribol Int 153: 106597

42. Krolczyk GM, Maruda RW, Krolczyk JB, Wojciechowski S, Mia M, Nieslony P et al (2019) Ecological trends in machining as a key factor in sustainable production - a review. J Clean Prod 218:601615. https://doi.org/10.1016/j.jclepro.2019.02.017

43. Haq MA ul, Hussain S, Ali MA, Farooq MU, Mufti NA, Pruncu CI, et al. (2021) Evaluating the effects of nano-fluids based MQL milling of IN718 associated to sustainable productions. J Clean Prod 310:127463. https://doi.org/10.1016/j.jclepro.2021.127463 
44. Yakoubi K, Montassir S, Moustabchir H, Elkhalfi A, Pruncu CI, Arbaoui J et al (2021) An extended finite element method (XFEM) study on the elastic T-stress evaluations for a notch in a pipe steel exposed to internal pressure. Mathematics 9:507. https://doi.org/10. 3390/math9050507

45. Yıldırım ÇV, Sarıkaya M, Kıvak T, Şirin Ş (2019) The effect of addition of $\mathrm{hBN}$ nanoparticles to nanofluid-MQL on tool wear patterns, tool life, roughness and temperature in turning of Ni-based Inconel 625. Tribol Int 134:443-456

46. Yıldırım ÇV (2019) Experimental comparison of the performance of nanofluids, cryogenic and hybrid cooling in turning of Inconel 625. Tribol Int 137:366-378

47. Yıldırım CV (2020) Investigation of hard turning performance of eco-friendly cooling strategies: cryogenic cooling and nanofluid based MQL. Tribol Int 144:106127

48. Şirin Ș, Sarıkaya M, Yıldırım ÇV, Kıvak T (2021) Machinability performance of nickel alloy X-7 hBN mixed nanofluid-MQL Tribol Int 153:106673. https://doi.org/10.1016/j.triboint.2020.106673

49. Peng DX, Kang Y, Hwang RM, Shyr SS, Chang YP (2009) Tribological properties of diamond and $\mathrm{SiO} 2$ nanoparticles added in paraffin. Tribol Int 42:911-917

50. Özbek NA, Çiçek A, Gülesin M, Özbek O (2016) Effect of cutting conditions on wear performance of cryogenically treated tungsten carbide inserts in dry turning of stainless steel. Tribol Int 94:223233

51. Azam M, Jahanzaib M, Wasim A, Hussain S (2015) Surface roughness modeling using RSM for HSLA steel by coated carbide tools. Int J Adv Manuf Technol 78:1031-1041

52. Touggui Y, Belhadi S, Mechraoui S-E, Uysal A, Yallese MA, Temmar M (2020) Multi-objective optimization of turning parameters for targeting surface roughness and maximizing material removal rate in dry turning of AISI 316L with PVD-coated cermet insert. SN Applied Sciences 2:1-14

53. Das SR, Panda A, Dhupal D (2017) Experimental investigation of surface roughness, flank wear, chip morphology and cost estimation during machining of hardened AISI 4340 steel with coated carbide insert. Mechanics of Advanced Materials and Modern Processes 3:9

54. Jawad M, Jahanzaib M, Ali MA, Farooq MU, Mufti NA, Pruncu CI et al (2021) Revealing the microstructure and mechanical attributes of pre-heated conditions for gas tungsten arc welded AISI 1045 steel joints. Int J Press Vessel Pip 192:104440. https://doi.org/10. 1016/j.ijpvp.2021.104440

55. Khan SA, Rehman M, Farooq MU, Ali MA, Naveed R, Pruncu CI et al (2021) A detailed machinability assessment of DC53 steel for die and mold industry through wire electric discharge machining. Metals 11:816. https://doi.org/10.3390/met11050816

56. Mughal MP, Farooq MU, Mumtaz J, Mia M, Shareef M, Javed M et al (2021) Surface modification for osseointegration of Ti6Al4V ELI using powder mixed sinking EDM. J Mech Behav Biomed Mater 113:104145. https://doi.org/10.1016/j.jmbbm.2020.104145

57. Farooq MU, Ali MA, He Y, Khan AM, Pruncu CI, Kashif M et al (2020) Curved profiles machining of Ti6Al4V alloy through WEDM: investigations on geometrical errors. J Mater Res Technol 9:16186-16201. https://doi.org/10.1016/j.jmrt.2020.11. 067

Publisher's note Springer Nature remains neutral with regard to jurisdictional claims in published maps and institutional affiliations. 